\title{
Lignocellulose-Based Superabsorbent Polymer Gel Crosslinked with Magnesium Aluminum Silicate for Highly Removal of Zn (II) from Aqueous Solution
}

\author{
Yuhong An ${ }^{1,+}{ }^{+}$, Wanqi Zhang ${ }^{1,+}{ }^{+}$, Hui Liu ${ }^{1}$, Yuan Zhong ${ }^{1}$, Zichu Hu ${ }^{2}$, Yali Shao ${ }^{1}$, Zhangjing Chen ${ }^{3}$, Yukun Ren ${ }^{4}$, \\ Boyun Wang ${ }^{2}$, Sunguo Wang ${ }^{5}$, Xiaotao Zhang ${ }^{2,6, *(1)}$ and Ximing Wang ${ }^{1,6, *}$ \\ 1 College of Material Science and Art Design, Inner Mongolia Agricultural University, Hohhot 010018, China; \\ anyuhong@emails.imau.edu.cn (Y.A.); nmgndcyyzwq@emails.imau.edu.cn (W.Z.); \\ nndcyylh@emails.imau.edu.cn (H.L.); zhongyuan@emails.imau.edu.cn (Y.Z.); \\ shaoyali_lucky@emails.imau.edu.cn (Y.S.) \\ 2 College of Science, Inner Mongolia Agricultural University, Hohhot 010018, China; \\ huzichu@emails.imau.edu.cn (Z.H.); 13485473614@emails.imau.edu.cn (B.W.) \\ 3 Department of Sustainable Biomaterials, Virginia Polytechnic Institute and State University, \\ Blacksburg, VA 24060, USA; chengo@vt.edu \\ 4 Bioimaging Research, Sanofi Global R\&D, Framingham, MA 01702, USA; yukun.ren@sanofi.com \\ 5 Sungro Bioresource \& Bioenergy Technologies Corp., Edmonton, AL T6R3J6, Canada; \\ wangsunguo@gmail.com \\ 6 Inner Mongolia Key Laboratory of Sandy Shrubs Fibrosis and Energy Development and Utilization, \\ Hohhot 010018, China \\ check for \\ * Correspondence: xiaotaozhang@imau.edu.cn (X.Z.); wangximing@imau.edu.cn (X.W.) \\ + Contributed equally to this paper.
}

Citation: An, Y.; Zhang, W.; Liu, H.; Zhong, Y.; Hu, Z.; Shao, Y.; Chen, Z.; Ren, Y.; Wang, B.; Wang, S.; et al. Lignocellulose-Based Superabsorbent Polymer Gel Crosslinked with Magnesium Aluminum Silicate for Highly Removal of Zn (II) from Aqueous Solution. Polymers 2021, 13, 4161. https://doi.org/10.3390/ polym13234161

Academic Editor: Antonio Pizzi

Received: 9 November 2021

Accepted: 25 November 2021

Published: 28 November 2021

Publisher's Note: MDPI stays neutral with regard to jurisdictional claims in published maps and institutional affiliations.

Copyright: (C) 2021 by the authors Licensee MDPI, Basel, Switzerland. This article is an open access article distributed under the terms and conditions of the Creative Commons Attribution (CC BY) license (https:// creativecommons.org/licenses/by/ $4.0 /)$.

\begin{abstract}
Lignocellulose (LCE) was ultrasonically treated and intercalated into magnesium aluminum silicate (MOT) clay to prepare a nano-lignocellulose magnesium aluminum silicate polymer gel (nanoLCE-MOT) for the removal of $\mathrm{Zn}$ (II) from aqueous solution. The product was characterised using nitrogen adsorption/desorption isotherm measurements, Fourier-transform infrared spectroscopy, scanning electron microscopy and energy-dispersive $\mathrm{X}$-ray spectroscopy. The conditions for the adsorption of $\mathrm{Zn}$ (II) on nano-LCE-MOT were screened, and adsorption kinetics and isotherm model analysis were carried out to explore the adsorption mechanism and achieve the optimal adsorption of $\mathrm{Zn}$ (II). Optimal adsorption was achieved at an initial $\mathrm{Zn}$ (II) concentration of $800 \mathrm{mg} / \mathrm{L}$ at $60{ }^{\circ} \mathrm{C}$ in $160 \mathrm{~min}$ at a $\mathrm{pH}$ of 4.52 . The adsorption kinetics were explored using a pseudo-second-order model, with the isotherm adsorption equilibrium found to conform to the Langmuir model. The maximum adsorption capacity of the nano-LCE-MOT polymer gel toward Zn (II) is $513.48 \mathrm{mg} / \mathrm{g}$. The materials with adsorbed $\mathrm{Zn}$ (II) were desorbed using different media, with $\mathrm{HCl}$ found to be the most ideal medium to desorb $\mathrm{Zn}$ (II). The optimal desorption of $\mathrm{Zn}$ (II) was achieved in $0.08 \mathrm{~mol} / \mathrm{L}$ $\mathrm{HCl}$ solution at $65^{\circ} \mathrm{C}$ in $60 \mathrm{~min}$. Under these conditions, $\mathrm{Zn}$ (II) was almost completely desorbed from the adsorbents, with the adsorption effect after cycling being slightly different from that of the initial adsorption.
\end{abstract}

Keywords: nano-lignocellulose; magnesium aluminum silicate; intercalation; adsorption; Zn (II)

\section{Introduction}

Heavy metals that are released into the environment tend to persist indefinitely, circulate and eventually accumulate throughout the food chain, posing a serious threat to the environment, animals and humans [1-3]. Even at relatively low concentrations, heavy metals are toxic to aquatic flora and fauna, and in some of these organisms they are assimilated, stored and concentrated. In the presence of zinc sulphides, carbonates, silicates, and oxides are formed in Nature. The presence of $\mathrm{Zn}$ (II) at $\mathrm{pH}<7$ is negligible, but at $\mathrm{pH}>7$ it is present in different forms. $\mathrm{Zn}$ (II) is discharged in the wastewater of the waste streams of metal, chemical and pulp 
and paper processes, from galvanised steel plant lines, plant zinc and brass metal processes, $\mathrm{Zn}$ (II) and brass plating and processes such as viscose rayon fibre production. The World Health Organization recommends a maximum acceptable zinc concentration limit in water of $5.0 \mathrm{mg} \mathrm{L}^{-1}$ [4]. Zn (II) plays a regulatory role in the immune system of the human body, maintaining normal physiological functions in adults, promoting the normal development of children, and promoting the healing of ulcers. It is often used to treat children with anorexia, malnutrition and slow growth, and can also be used to treat hair loss, rashes, mouth ulcers and gastritis. An excess intake of Zn (II) can cause astringency, thirst, a tight chest, dry cough, headaches, dizziness, high fever and chills, among other symptoms. Zn (II) dust is irritating to the eyes and when orally ingested affects the gastrointestinal tract. With this in mind, there are many treatment technologies available to purify water and wastewater contaminated with such heavy metals. The most common methods for removing metal ions from wastewater include chemical precipitation [5,6], extraction [7], redox [8], dialysis [9], electrodialysis [10], electrolytic extraction [11], reverse osmosis [12,13], ion exchange [14,15], adsorption [16-20], ion flotation [21], stripping [22], coagulation flocculation [23], precipitation [24,25] and chelation [26]. Among them, adsorption is widely used as an environmentally friendly method, especially for metal ions that cannot be removed using other techniques. Selective adsorption can also be carried out using biomass materials, such as inorganic clay, activated carbon or polymer resins.

Lignocellulose (LCE) is widely used as a natural biodegradable raw material in the preparation of various biomass absorbent [27]. As the most abundant renewable resource in nature, LCE is widely used in the research and development of new materials, not only because it is cheap and easy to obtain, but more importantly, because it contains lignin, cellulose and hemicellulose. These three components have different properties and can thus be used to change the properties of other materials, whether isolated or used directly [28]. The cellulose, lignin and hemicellulose in LCE are tightly entangled, which results in LCE having a high molecular weight and being difficult to combine with other materials [29,30]. To reduce the molecular weight of LCE and free up functional groups to facilitate the reaction of LCE with other materials, chemical [31] and mechanical methods [32-34], as well as a combination of the two, have been employed.

Magnesium aluminum silicate (MOT), the most common layered silicate, is commonly used to prepare absorbents due to its high cation exchange capacity (CEC), surface area, surface reactivity, adsorption performance and low cost $[35,36]$. MOT has a nanoscale flat sheet layer structure, with this special structure leading to the sheets of MOT being permanently negatively charged, meaning that it exhibits strong exchangeability and adsorption toward positively charged metal cations. The sheet bonding strength of MOT is very weak; thus, it is highly likely that its sheet layers are translated or even peel off, meaning that MOT also exhibits intercalation properties. However, the adsorption capacity of MOT is insufficient, meaning that it cannot be used in large-scale applications. To form MOT absorbent, a monomer or polymer is inserted into the sheet structure of MOT to break its sheet structure. Therefore, to increase its adsorption capacity for $\mathrm{Zn}$ (II) cations, MOT can be reacted with nanosized LCE (nano-LCE) to form a polymer gel adsorbent via the attachment of the absorptive functional groups of nano-LCE to the structure of the MOT. Lignocellulose has a large number of hydroxyl groups on its surface, and its fibres are tightly bound via hydrogen bonding, meaning that it exhibits strong polarity and water absorption. The hydrophilic polarity of the lignocellulose surface means that it adsorbs moisture and dissolved substances from water. When a polymer gel is formed from nano-LCE and MOT, nano-LCE is dispersed in the MOT layers, wherein a large number of intermolecular amino bonds are formed between the hydroxyl groups of MOT and the hydroxyl groups of the nano-LCE between the sheets, enhancing the forces between the fibres to form a structurally stable polymer gel material. In this polymer gel, the adsorption performance and the electronegativity of MOT increase the overall adsorption capacity toward Zn (II) cations. Compare with the same type of clay mineral polymer composite material [37-39]. This paper uses dissolution and ultrasonic cavitation effects to disperse 
the LCE, and then insert the dispersed nano-LCE between the magnesium-aluminum silicate clay sheets to re-polymerize the layers to form a stable Three-dimensional network structure similar to that of wood cell walls. Structure to obtain a super absorbent polymer gel with high specific surface area and multiple adsorption sites.

\section{Materials and Methods}

\subsection{Materials}

Zinc oxide $(\mathrm{ZnO}$, analytical grade reagent, $\mathrm{AR})$ was purchased from Sinopharm Chemical Reagent Co., Ltd. (Beijing, China). Sulfuric acid $\left(\mathrm{H}_{2} \mathrm{SO}_{4}, \mathrm{AR}\right)$ was purchased from Sinopharm Chemical Reagent Co., Ltd. (Beijing, China). Sodium hydroxide ( $\mathrm{NaOH}$, AR) was purchased from Tianjin Fengchuan Chemical Reagent Co., Ltd. (Tianjin, China). MOT (CEC of $100 \mathrm{meq} \cdot 100 \mathrm{~g}^{-1}$ ) was produced by Zhejiang Fenghong Clay Chemical Co., Ltd. (Huzhou, China). LCE (SAM-100) was produced by Beijing Huaduo Biotech, Ltd. (Beijing, China). All solutions used in the experiments were prepared using distilled water.

\subsection{Preparation of the LCE-MOT Polymer Gel}

LCE $(0.5 \mathrm{~g})$ was weighed into a $50 \mathrm{~mL}$ conical flask containing a $25 \%$ solution of $\mathrm{NaOH}(15 \mathrm{~mL})$, which was then placed in a temperature-controlled magnetic stirrer (HJ-6, Changzhou Guohua Instrument Co., Ltd., Changzhou, China) The mixture was then stirred at $50{ }^{\circ} \mathrm{C}$ for $30 \mathrm{~min}$ to fully expose the LCE to $\mathrm{NaOH}$. Then, MOT $(0.5 \mathrm{~g})$ was placed in a $50 \mathrm{~mL}$ beaker, to which $15 \mathrm{~mL}$ of deionised water was added, and the mixture was stirred at room temperature $\left(23-27^{\circ} \mathrm{C}\right)$ for $30 \mathrm{~min}$. When the MOT was sufficiently dispersed in the deionised water it was assumed that MOT and LCE were mixed, and the resultant mixture was stirred on a temperature-controlled magnetic stirrer at $50{ }^{\circ} \mathrm{C}$ for $4 \mathrm{~h}$. After this time, the product was washed with deionised water until $\mathrm{pH} 7$ was reached, then dried at $85^{\circ} \mathrm{C}$ for $4 \mathrm{~h}$ (DZF-6210, Shanghai Yiheng Scientific Instrument Co., Ltd., Shanghai, China), before being pulverised into a powder, and sieved through a 200-size mesh.

\subsection{Preparation of Nano-LCE}

A $20 \mathrm{wt}$ \% solution of $\mathrm{NaOH}(250 \mathrm{~mL})$ was prepared and poured into a $250 \mathrm{~mL}$ beaker. Then, to this, LCE (0.5 g) was gradually added, and the mixture was slowly stirred with a glass rod until a suspension was formed. The stirred suspension was placed in a SM-1200D ultrasonic cell pulveriser (Nanjing Shunma Co., Ltd., Nanjing, China) and treated at $1080 \mathrm{~W}$ for $150 \mathrm{~min}$, before being removed and centrifuged to obtain the target nano-LCE material.

\subsection{Preparation of the Nano-LCE-MOT Polymer Gel}

The prepared nano-LCE was centrifuged and re-dispersed in a $25 \%$ solution of $\mathrm{NaOH}$ $(15 \mathrm{~mL})$ and added to a $50 \mathrm{~mL}$ Erlenmeyer flask. Then, the same experimental conditions used in the preparation of the LCE-MOT polymer gel were used to prepare the nano-LCEMOT polymer gel. After the preparation was completed, the product was freeze-dried and used for subsequent adsorption experiments.

\subsection{Adsorption Experiments}

A Zn (II) ion solution (100 mL) was prepared for adsorption and added to a $250 \mathrm{~mL}$ milled Erlenmeyer flask. Hydrochloric acid $(\mathrm{HCl})$ or $\mathrm{NaOH}(0.1 \mathrm{~mol} / \mathrm{L})$ was then used to adjust the $\mathrm{pH}$ of the solution to the experimental target value. The adsorbent $(0.05 \mathrm{~g}$ of the LCE-MOT polymer gel or nano-LCE-MOT polymer gel) was added to the ionic solution, and the flask was then sealed with a glass stopper and placed in a thermostatic shaker (TED, Tianjin Taisite Instrument Co., Ltd., Tianjin China). The adsorption temperature and time were set to complete the adsorption experiments at a constant speed of $120 \mathrm{rpm}$. After the adsorption process was completed, the resultant mixture was centrifuged at $3000 \mathrm{rpm}$ for $7 \mathrm{~min}$. The Zn (II) concentration of the supernatant was measured using the xylenol orange complex colorimetric method, and the colourised $\mathrm{Zn}$ (II) ion solution was then passed through a dual-beam ultraviolet-visible spectrophotometer (TU-1901, Beijing 
General Analysis General Instruments Co., Ltd., Beijing, China) to measure the absorbance of the $\mathrm{Zn}$ (II) complex. A linear regression equation $\left(\mathrm{y}=0.3297 \mathrm{x}+0.409, \mathrm{R}^{2}=0.9998\right)$ was then used to determine the concentration of the $\mathrm{Zn}$ (II) solution and the amount of $\mathrm{Zn}$ (II) adsorbed on the adsorbent. Taking experimental errors and averages into account, three independent replicate experiments confirmed that the $\mathrm{Zn}$ (II) removal was reproducible under the same conditions. The amount of metal adsorbed (qt) at equilibrium at time $t$ was calculated using Equation (1):

$$
\mathrm{q}_{\mathrm{t}}=\frac{\left(\mathrm{C}_{0}-\mathrm{C}_{\mathrm{t}}\right) \times \mathrm{V}_{0}}{\mathrm{~m}_{0}}
$$

where $\mathrm{q}_{\mathrm{t}}(\mathrm{mg} / \mathrm{g})$ is the capacity of the adsorption at time $\mathrm{t} ; \mathrm{C}_{0}$ and $\mathrm{Ct}(\mathrm{mg} / \mathrm{L})$ are the initial concentration and concentration of $\mathrm{Zn}$ (II) at time $\mathrm{t}$, respectively; $\mathrm{V}_{0}$ (L) is the volume of the $\mathrm{Zn}$ (II) ion solution and $\mathrm{m}_{0}(\mathrm{~g})$ is the mass of the adsorbent.

\subsection{Desorption Experiments}

$\mathrm{HCl}, \mathrm{HNO}_{3}, \mathrm{H}_{2} \mathrm{SO}_{4}$ and $\mathrm{NaOH}$ solutions used as desorption reagents were prepared at different concentrations. Saturated adsorbent $(0.05 \mathrm{~g})$ was weighed into a $250 \mathrm{~mL}$ conical flask, to which $50 \mathrm{~mL}$ of the desorption reagents were added, and ultrasonic desorption was carried out for a certain time at a certain temperature until desorption equilibrium was reached. The suspension was then centrifuged, and the metal ion concentration in the supernatant of each desorption experiment was tested using the previously mentioned method. The desorption experiments were conducted three times in the same manner, and the desorption capacity at equilibrium $\left(\mathrm{q}_{\mathrm{t}, 2}\right)$ was calculated using the following equation:

$$
\mathrm{q}_{\mathrm{t}, 2}=\frac{\mathrm{C}_{\mathrm{t}, 2} \times \mathrm{V}_{2}}{\mathrm{~m}_{2}}
$$

where $\mathrm{q}_{\mathrm{t}, 2}(\mathrm{mg} / \mathrm{g})$ is the amount of $\mathrm{Zn}(\mathrm{II})$ desorbed at desorption time $\mathrm{t}(\mathrm{min}) ; \mathrm{C}_{\mathrm{t}, 2}(\mathrm{mg} / \mathrm{L})$ is the concentration of each metal ion in solution at time $t(\mathrm{~min}) ; \mathrm{V}_{2}(\mathrm{~mL})$ is the volume of the desorption agents and $\mathrm{m}_{2}(\mathrm{~g})$ is the final mass of the adsorbents after release of the metal ions.

Adsorption/desorption cycling tests were carried out to investigate the reusability of the nano-LCE-MOT and LCE-MOT. The nano-LCE-MOT and LCE-MOT were washed until they were restored to their original states after the first batch of adsorption experiments and were then used in the subsequent adsorption experiments. The regenerated nano-LCEMOT and LCE-MOT were then used in three consecutive cycles under identical conditions and the residual $\mathrm{Zn}$ (II) in solution after each adsorption/desorption cycle was measured using the previously mentioned method, and the adsorption/desorption capacity was calculated using the above equations.

\section{Results}

\subsection{Characterisation of the Materials}

The physicochemical properties of the nano-LCE-MOT polymer gel were investigated using different characterisation techniques. The specific surface area, pore structure and pore size of nano-LCE-MOT were measured from nitrogen $\left(\mathrm{N}_{2}\right)$ adsorption-desorption isotherms at $-77^{\circ} \mathrm{C}$ using an ASAP 2020 surface area analyser (Micromeritics, South Bend, IN, USA). The specific surface area was measured using the Langmuir and BrunauerEmmet-Teller (BET) methods. Chemical characterisation of the functional groups of TL and TLM was carried out using a spectrophotometer (Thermo Nicolet corporation, Madison, WI, USA) over a scan range of $4000-400 \mathrm{~cm}^{-1}$. The powder X-ray diffraction (PXRD) pattern of the TLM was recorded using a diffractometer (X'pero PRO, Armelo, The Netherlands) equipped with a $\mathrm{K} \alpha$ radiation source in the $2 \theta$ angle range of $2-15^{\circ}$, operated at $40 \mathrm{kV}$ and $30 \mathrm{~mA}$. Scanning electron microscopy (SEM) of TLM was performed using HITACHI S-4800 (Tokyo, Japan) and S-3400/N Oxford-XMasN (HORIBA, Kyoto, Japan) 
microscopes. Meanwhile, transmission electron microscopy (TEM, JEM-2010, JEOL, Tokyo, Japan) was carried out at 75-100 kV to investigate the morphology and structure of TLM.

\subsection{1. $\mathrm{N}_{2}$ Adsorption-Desorption Isotherms of the Nano-LCE-MOT Polymer Gel}

The $\mathrm{N}_{2}$ adsorption/desorption isotherms of LCE-MOT and nano-LCE-MOT are shown in Figure 1a,b, respectively. From Figure 1a,b, it can be observed that LCE-MOT exhibits a type II-shaped isotherm, with a $\mathrm{H}_{3}$ hysteresis loop in the middle of the curve, while nano-LCE-MOT exhibits a type IV-shaped isotherm, with a $\mathrm{H}_{4}$ hysteresis loop in the middle of the curve, indicating that there are a lot of slit pores in the nano-LCE-MOT, which is different from particle accumulation and is a result of its layered structure [40]. According to Table 1, the average pore size of LCE-MOT is around $31.82 \mathrm{~nm}$, whereas that of nano-LCE-MOT is smaller at around $6.17 \mathrm{~nm}$. Meanwhile, the specific surface area of LCE-MOT was calculated using the Langmuir method $\left(378.06 \mathrm{~m}^{2} / \mathrm{g}\right)$ and the BET $\left(213.50 \mathrm{~m}^{2} / \mathrm{g}\right)$ methods, and that of nano-LCE-MOT was found to be higher at $701.80 \mathrm{~m}^{2} / \mathrm{g}$ (Langmuir method) and $532.74 \mathrm{~m}^{2} / \mathrm{g}$ (BET method). The experimental results indicate that the specific surface area, pore volume and mean pore size of nano-LCE-MOT were enhanced to varying degrees after its nanosizing treatment, with its increased parameters enhancing its adsorption capacity toward Zn (II) [37].
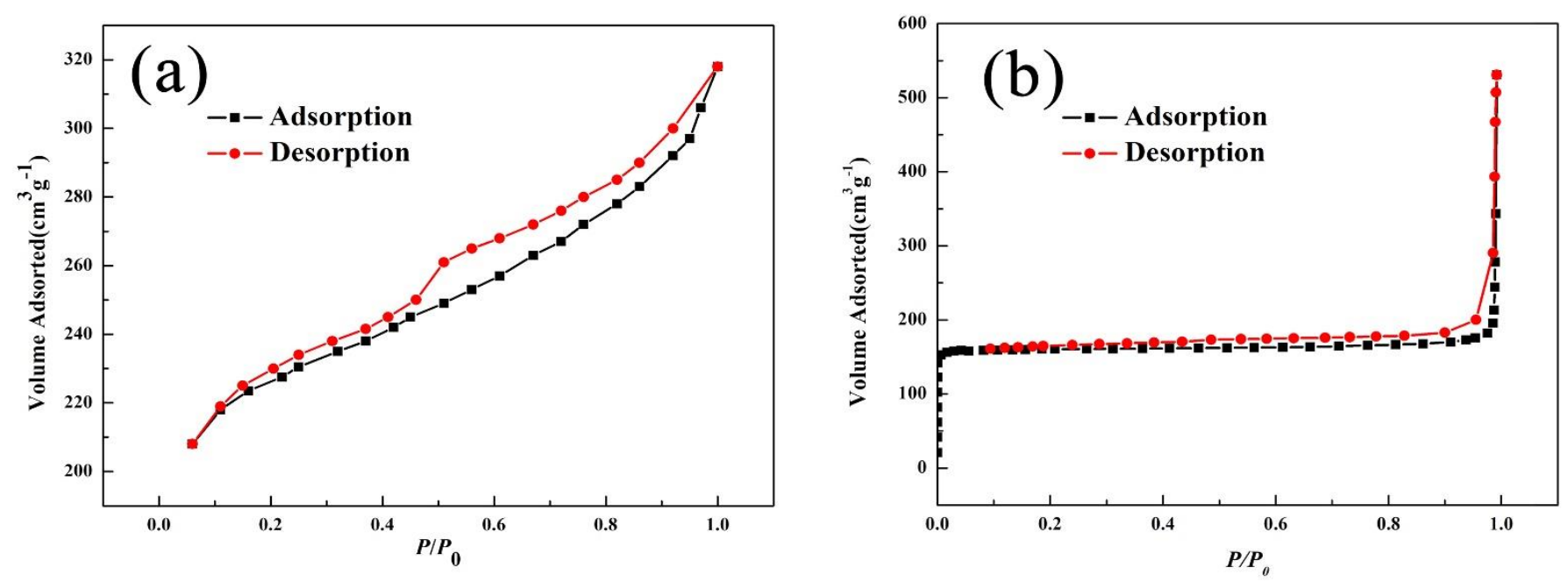

Figure 1. (a), Adsorption-desorption curves of $\mathrm{N}_{2}$ on lignocellulose magnesium aluminum silicate polymer gel (LCE-MOT) LCE-MOT. (b), Adsorption-desorption curves of $\mathrm{N}_{2}$ on Nano-LCE-MOT.

Table 1. Surface area and pore structure parameters of MOT, LCE-MOT, Nano-LCE-MOT.

\begin{tabular}{ccccccc}
\hline Sample & SBET $\left(\mathbf{m}^{2} / \mathbf{g}\right)$ & SLangmuir $\left(\mathbf{m}^{2} / \mathbf{g}\right)$ & VMic $\left(\mathbf{c m}^{3} / \mathbf{g}\right)$ & RMic $(\mathbf{n m})$ & Rmes $(\mathbf{n m})$ & RAve $(\mathbf{n m})$ \\
\hline MOT & 61.4 & 137.52 & 0.024 & & 1.98 & 45.93 \\
LCE-MOT & 213.50 & 378.06 & 1.051 & 0.25 & 31.82 \\
Nano-LCE-MOT & 532.74 & 701.80 & 0.68 & 173.02 & 6.17 \\
\hline
\end{tabular}

\subsubsection{FTIR Analysis of the Materials}

The characteristic chemical structures of MOT, LCE, nano-LCE, LCE-MOT and nano-LCEMOT were characterised by FTIR spectroscopy in the wavenumber range of $4000-400 \mathrm{~cm}^{-1}$. Figure 2 shows the FTIR spectrum of LCE, which features peaks that can be attributed to $-\mathrm{OH}$ bending $\left(3366 \mathrm{~cm}^{-1}\right)$, the $-\mathrm{OH}$ stretching vibration of -COOH $\left(1462 \mathrm{~cm}^{-1}\right)$ and the -C-O-Cstretching vibration of cellulose and hemicellulose $\left(1050 \mathrm{~cm}^{-1}\right)$ [41], while after nanosizing treatment, the absorption peaks were shifted to 3360,1474 and $1037 \mathrm{~cm}^{-1}$, respectively, and a new peak attributed to $-\mathrm{C}=\mathrm{O}$ appeared at $1622 \mathrm{~cm}^{-1}$ [42], indicating that the active groups of lignocellulose were exposed after the nanosizing treatment. From the results shown in 
Figure 2, it is inferred that the nanosizing treatment of LCE does not change its chemical structure, it only reduces its size to nanosized, thus enhancing its adsorption capacity toward Zn (II) from effluent.

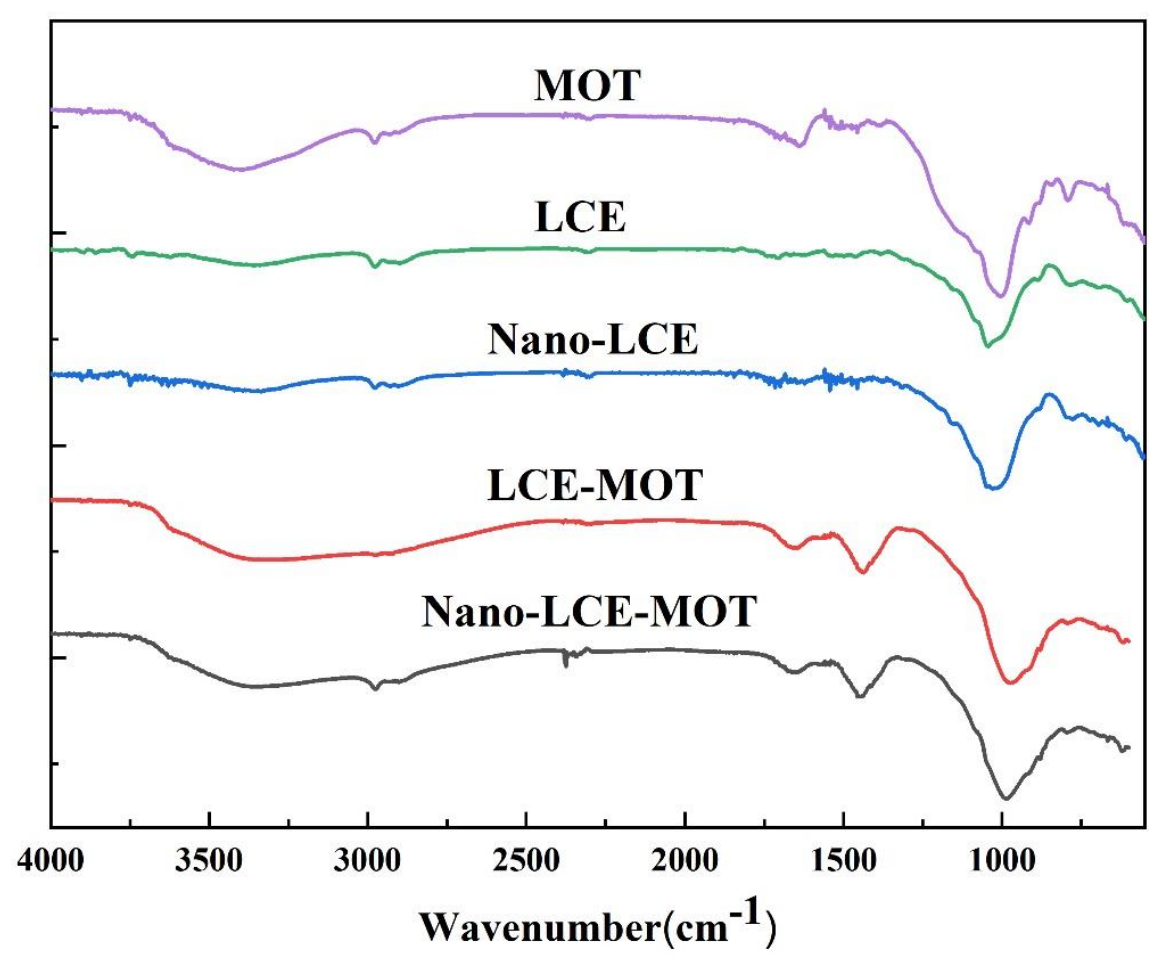

Figure 2. FTIR spectra of MOT, LCE, Nano-LCE, LCE-MOT, Nano-LCE-MOT.

Upon the intercalation of LCE and nano-LCE into the interlayers of MOT, the peak of $-\mathrm{OH}\left(3406 \mathrm{~cm}^{-1}\right)$ shifted to a higher wavenumber of $3468 \mathrm{~cm}^{-1}$ for LCE-MOT and $3438 \mathrm{~cm}^{-1}$ for nano-LCE-MOT, and the carbonyl -OH absorption peak shifted to 1464 and $1456 \mathrm{~cm}^{-1}$, respectively. The telescopic vibration adsorption peaks at 909 and $786 \mathrm{~cm}^{-1}$ can be attributed to $-\mathrm{Al}-\mathrm{O}-\mathrm{H}$ and $-\mathrm{Si}-\mathrm{O}$ in in the structure of MOT, respectively, and they were clearly abated, as is evident from the spectra of LCE-MOT and nano-LCE-MOT [43]. As shown in the FTIR spectra, LCE and nano-LCE intercalate into the interlayers of MOT, and there are many different types of adsorption sites on the surface of LCE-MOT and nanoLCE-MOT, such as - Al-O, -Si-O, - $-\mathrm{C}-\mathrm{O}-\mathrm{C}-,-\mathrm{C}=\mathrm{O}$ and $-\mathrm{OH}$, which enhance their capacity to adsorb heavy metals [44].

\subsubsection{PXRD Analysis of the Materials}

As shown in Figure 3, the PXRD pattern of MOT exhibits a characteristic diffraction peak at $5.92^{\circ}$, which indicates that it maintains a relatively complete crystal structure and has a typical nanomaterial structure [45]. After the intercalation reaction of MOT with LCE and nano-LCE, the characteristic diffraction peak of MOT disappeared, indicating that the layered structure of MOT is destroyed during the intercalation process as LCE and nano-LCE enter into the layers of MOT, forming an intercalation stripped nanostructure. Apparently, in the intercalation process, nano-LCE inflicts greater damage on the layered structure of the MOT, so the specific surface area of nano-LCE-MOT is higher than LCE-MOT.

\subsubsection{SEM Analysis of Nano-LCE-MOT and LCE-MOT}

To further investigate the microstructures of LCE-MOT and nano-LCE-MOT, their intercalation and exfoliation were analysed, and their surface morphologies were observed by SEM. It can be seen from Figures 2 and $4 a$ that the surfaces of LCE-MOT and nano-LCEMOT are very rough and dispersed, and their lamellar structures exhibit curly shapes. The 
results indicate that nano-LCE destroys the lamellar crystal structure of MOT and enters its interlayer domain, which is consistent with the PXRD results.

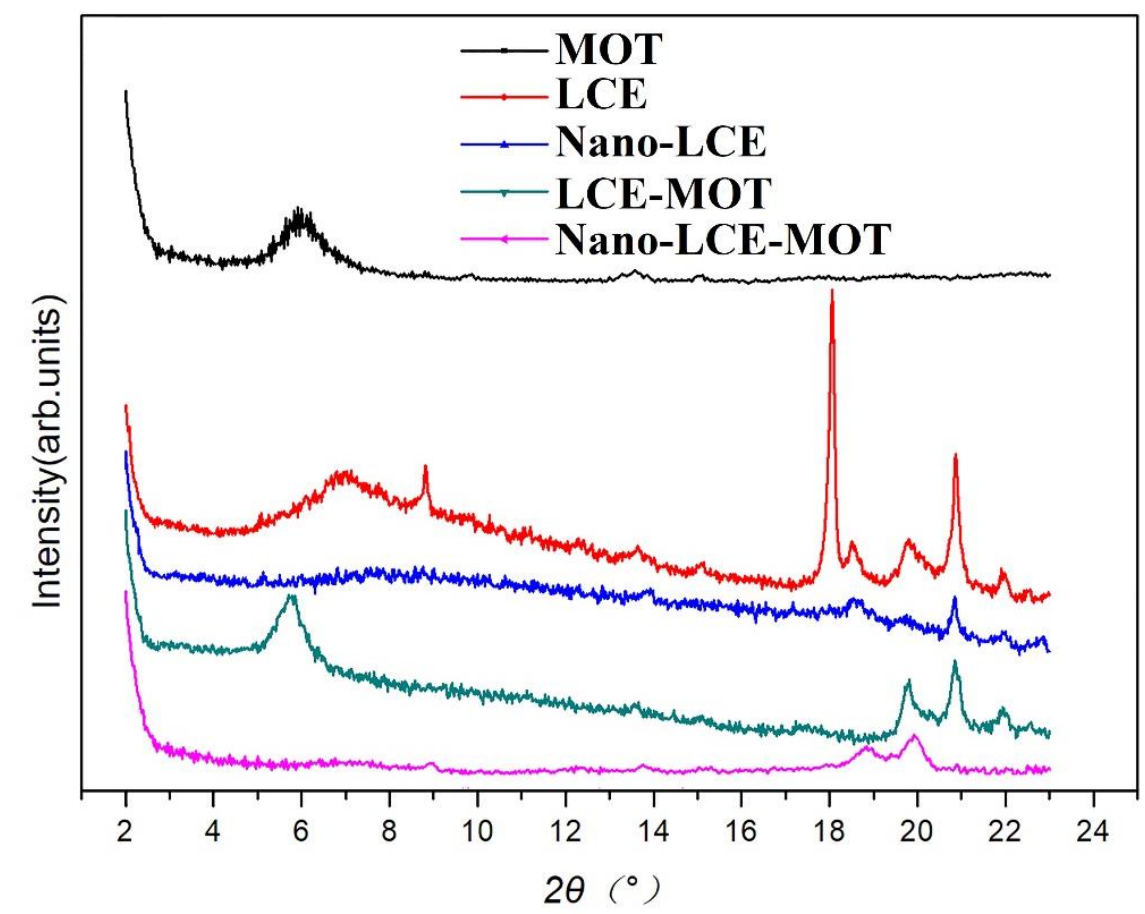

Figure 3. XRD patterns of MOT, LCE, Nano-LCE, LCE-MOT, Nano-LCE-MOT.

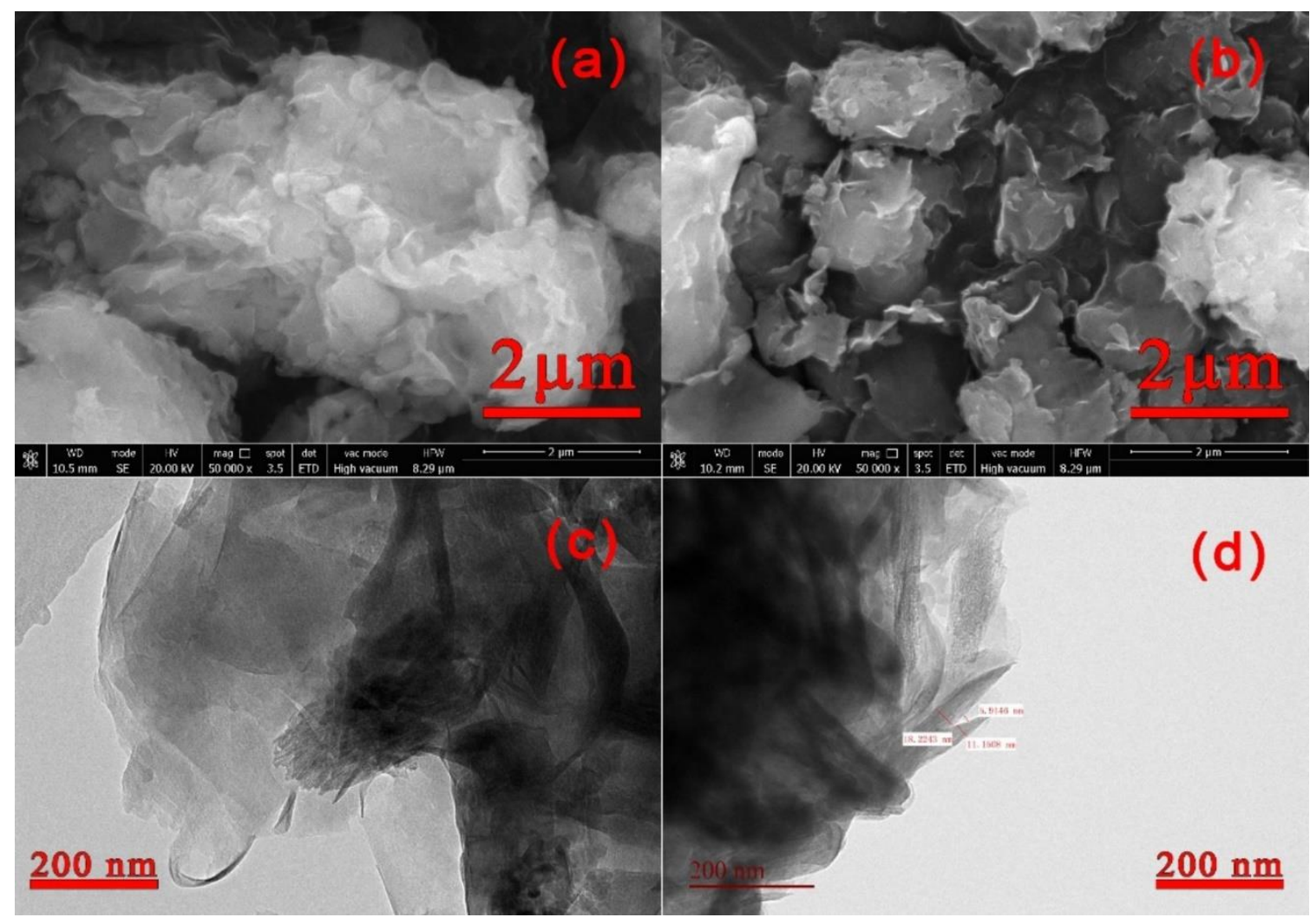

Figure 4. (a), SEM of LCE-MOT. (b), SEM of Nano-LCE-MOT. (c), TEM of LCE-MOT. (d), TEM of Nano-LCE-MOT. 


\subsubsection{TEM Analysis of Nano-LCE-MOT and LCE-MOT}

The morphologies and structures of LCE-MOT and nano-LCE-MOT were investigated using TEM. From the results, it can be seen that LCE and nano-LCE intercalate into the MOT layers and destroy the MOT structure. In Figure 4c,d, the shaded part is the lamellar structure of MOT, and the black rods are LCE (c) and nano-LCE (d). As the particle size of nano-LCE is smaller than that of LCE, it more easily enters into the MOT lamellae, which means that the black area in Figure 4d is more obvious than that in Figure 4c, so the specific surface area of nano-LCE-MOT is the highest of the polymer gel materials, and there are more active adsorption sites for the adsorption of heavy metals. Thus, the MOT lamellar crystals are stretched or stripped to form intercalation stripped materials.

\subsection{Adsorption Studies}

\subsubsection{Effect of the Initial Zn (II) Concentration}

Figure $5 \mathrm{a}, \mathrm{b}$ show the effect of the concentration of $\mathrm{Zn}$ (II) on the adsorption equilibrium behaviour of LCE-MOT and nano-LCE-MOT as Zn (II) adsorption materials. It is shown that the adsorption capacity of Zn (II) using LCE-MOT (0.65-4.58 g/L for Zn (II)) and nano-LCE-MOT (500-1000 mg/L for Zn (II)) increased in line with a higher initial metal concentration until maximum capacity was reached, but the maximum adsorption capacity of nano-LCE-MOT was higher than that of LCE-MOT, with a maximum adsorption capacity of $412.83 \mathrm{mg} / \mathrm{g}$. The adsorption capacities of LCE-MOT and nano-LCE-MOT exhibited maximum adsorption at initial Zn (II) concentrations of 3.27 and $800 \mathrm{mg} / \mathrm{L}$, respectively. When the concentration was lower at the beginning of the experiment, the adsorption of heavy metals was on the exterior surface of LCE-MOT and nano-LCE-MOT, yet with increasing concentration, the heavy metal ions were able to overcome the resistance due to mass transfer from the aqueous to solid phase and subsequently penetrated into the interior of the structure, giving rise to increasing numbers of adsorption sites on LCE-MOT and nano-LCE-MOT. The specific surface area of nano-LCE-MOT is therefore higher than that of LCE-MOT, so it has a higher number of adsorption sites than LCE-MOT, which leads to extra adsorption sites for Zn (II) to occupy on the surface of nano-LCE-MOT [46]. It is clear that the adsorption capacity did not change significantly after an additional increase in the metal concentration due to there being no more sites available for heavy metal adsorption on the LCE-MOT and nano-LCE-MOT surfaces.
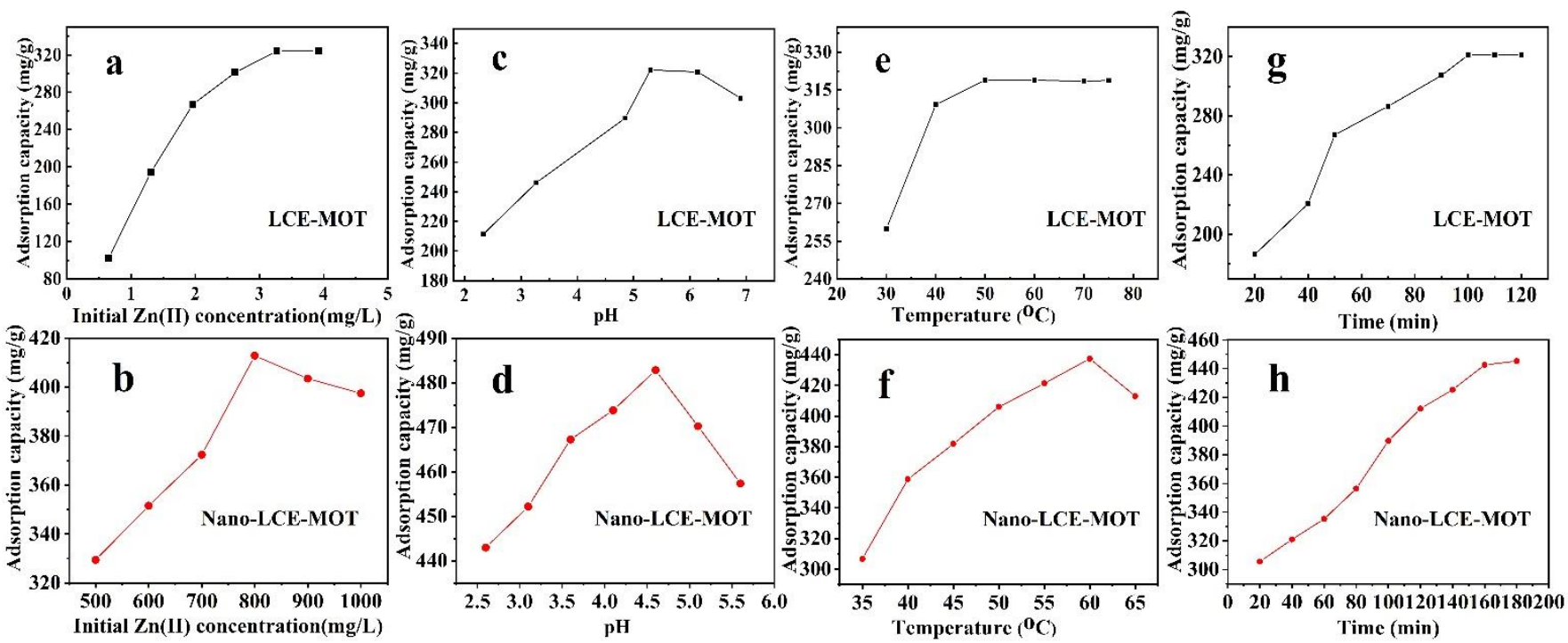

Figure 5. Effect of Zn (II) initial concentration on adsorption capacity of LCE-MOT (a) and Nano-LCE-MOT (b). Effect of $\mathrm{pH}$ on adsorption capacity of LCE-MOT (c) and Nano-LCE-MOT (d). Effect of Temperature on adsorption capacity of LCE-MOT (e) and Nano-LCE-MOT (f). Effect of Time on adsorption capacity of LCE-MOT (g) and Nano-LCE-MOT (h). 


\subsubsection{Effect of $\mathrm{pH}$}

Figure $5 \mathrm{c}, \mathrm{d}$ show the effects of the starting $\mathrm{pH}$ of the solution on the adsorption of $\mathrm{Zn}$ (II). As noted from the figures, the $\mathrm{pH}$ has a marked impact on the adsorption process of LCE-MOT and nano-LCE-MOT toward Zn (II). The adsorption capacities of $\mathrm{Zn}$ (II) were found to be enhanced with increasing $\mathrm{pH}$, and then slightly decreased upon a further increase in the $\mathrm{pH}$. The capacity for the adsorption of $\mathrm{Zn}$ (II) rose from 215 to $351 \mathrm{mg} / \mathrm{g}$ for LCE-MOT and 443 to $481 \mathrm{mg} / \mathrm{g}$ for nano-LCE-MOT upon an increase in $\mathrm{pH}$. Heavy metal adsorption is dependent on the interactions among the heavy metal ions and the active sites on the exterior of LCE-MOT and nano-LCE-MOT, which are impacted by the solution $\mathrm{pH}$. At low $\mathrm{pH}$, the competition between the $\mathrm{H}^{+}$ions and the adsorption sites on the LCE-MOT and nano-LCE-MOT surfaces became more intense in line with an increase in the $\mathrm{H}^{+}$concentration, thus leading to a decrease in adsorption capacity [47]. At low $\mathrm{pH}, \mathrm{Zn}$ (II) exists in the form of a dissolved metal, whereas at $\mathrm{pH}$ values of above approximately, $\mathrm{Zn}$ may precipitate out as $\mathrm{ZnOH}$ and $\mathrm{Zn}(\mathrm{OH})_{2}$, decreasing the percentage of adsorption [48]. Comparing the adsorption behaviour of LCE-MOT and nano-LCE-MOT toward Zn (II), the adsorption capacity of nano-LCE-MOT toward $\mathrm{Zn}$ is much higher than that of LCE-MOT, even at lower $\mathrm{pH}$, where similar behaviour is observed. The reason for this might be because as LCE undergoes nanosizing treatment, there are more adsorption sites on the surface of nano-LCE-MOT, meaning that under low adsorption conditions at low $\mathrm{pH}$, although the $\mathrm{H}^{+}$ions compete with the active sites, nano-LCE-MOT still has other sites at which Zn (II) can adsorb. Meanwhile, the specific surface area of LCE-MOT is lower than that of nano-LCE-MOT, resulting in the adsorption capacity of nano-LCE-MOT being higher than that of LCE-MOT. At higher $\mathrm{pH}$ values, the adsorption of $\mathrm{Zn}$ (II) ions decreased to different degrees. Therefore, $\mathrm{pH} 5.30$ for LCE-MOT and 4.52 for nano-LCE-MOT were selected as the $\mathrm{pH}$ values for use in subsequent experiments.

\subsubsection{Effect of Adsorption Temperature}

Figure $5 \mathrm{e}, \mathrm{f}$ show the adsorption characteristics of LCE-MOT and nano-LCE-MOT at different temperatures, from which it can be seen that with an increase in the temperature the adsorption capacities of LCE-MOT and nano-LCE-MOT increased gradually and reached peak adsorption capacities of 318 and $430 \mathrm{mg} / \mathrm{g}$, respectively, demonstrating that an increase in temperature is more favourable for improving the adsorption of the materials toward Zn (II). With an increase in the adsorption temperature, the rate at which the heavy metal ions pass through the material pores and the diffusion rate on the materials surface increase, which leads to an increase in the adsorption capacity [49]. At the same time, with an increase in temperature, nano-LCE-MOT exhibits higher energy, and the numbers of collisions between the active sites and heavy metal ions on its surface increase, which accounts for the adsorption capacity of nano-LCE-MOT toward Zn (II) being higher than that of LCE-MOT.

\subsubsection{Effect of Adsorption Time}

Figure $5 \mathrm{~g}$, $\mathrm{h}$ showsthe effect that the adsorption time has on the removal of $\mathrm{Zn}$ (II), from which it can be seen that $\mathrm{Zn}$ (II) adsorption follows a steady increasing trend with time and is rapid on the two materials in the early process of adsorption. As presented in Figure 5g,h, the adsorption capacities of the Zn (II) ions increased rapidly from 180 to $330 \mathrm{mg} / \mathrm{g}$ on LCE-MOT and 300 to $440 \mathrm{mg} / \mathrm{g}$ on nano-LCE-MOT, respectively, in line with an increase in the adsorption time. In the initial stage of the adsorption process, there is a big difference in the concentration between the internal and external heavy metal ions of the adsorption material, so the driving force of the diffusion of heavy metal ions into the material is large at the initial stage of adsorption. With an increase in the adsorption time, the number of available adsorption sites on the material gradually decreases until saturation is reached, and the adsorption capacity then reaches equilibrium [50]. After the nanosizing treatment of nano-LCE-MOT, the material has more adsorption sites on its surface, which means that nano-LCE-MOT takes longer than LCE-MOT to reach adsorption equilibrium. Therefore, 
the adsorption capacity of nano-LCE-MOT is higher than LCE-MOT toward Zn (II), and the time taken to reach adsorption equilibrium is slightly longer.

\subsubsection{Adsorption Kinetics and Mechanism}

Prediction of the adsorption rates provides important information regarding adsorption mechanisms. To this aim, to evaluate the adsorption mechanisms of nano-LCE-MOT and LCE-MOT, the experimental data at various adsorption times corresponding to the changes in adsorption capacity were fitted using pseudo-first order (Equation (3)) and pseudo-second order (Equation (4)) models:

$$
\begin{gathered}
\ln \left(\mathrm{q}_{\mathrm{et}}-\mathrm{q}_{\mathrm{t}}\right)=\ln \mathrm{q}_{\mathrm{et}}-\mathrm{k}_{1} \mathrm{t} \\
\frac{\mathrm{t}}{\mathrm{q}_{\mathrm{t}}}=\frac{\mathrm{t}}{\mathrm{q}_{\mathrm{e}}}+\frac{1}{\mathrm{k}_{2} \mathrm{q}_{\mathrm{e}}^{2}}
\end{gathered}
$$

where $\mathrm{q}_{\mathrm{e}}$ and $\mathrm{q}_{\mathrm{t}}$ are the amounts of heavy metal ions adsorbed $(\mathrm{mg} / \mathrm{g})$ at equilibrium and at time $\mathrm{t}(\mathrm{min})$, respectively; $\mathrm{k}_{1}\left(\mathrm{~min}^{-1}\right)$ is the pseudo-first-order rate constant and $\mathrm{k}_{2}$ $\left[\mathrm{g} \cdot(\mathrm{mg} / \mathrm{min})^{-1}\right]$ is the rate constant of the pseudo-second-order adsorption kinetic equation.

The validity of the pseudo-first order and pseudo-second-order models was tested by fitting the data to a straight line, with the results shown in Figure 6a-d. The respective parameters for the reaction kinetic and determination coefficients are given in Table 2. Through the fitting of the data to the equations (Table 2), the adsorption of $\mathrm{Zn}$ (II) by nano-LCE-MOT and LCE-MOT was found to fit the pseudo-second-order model. From the data, it could be inferred that there was almost no impact on the adsorption rate by mass diffusion at a constant adsorption time according to the pseudo-second-order kinetic reaction mechanism. This demonstrates that the adsorption mechanisms of nano-LCE-MOT and LCE-MOT are controlled primarily by chemisorption [51]. Apparently, the maximum adsorption capacity of nano-LCE-MOT toward Zn (II) was higher than that of LCE-MOT, which might be related to the nanosizing treatment of LCE, which increases the number of adsorption sites on the surface of nano-LCE-MOT that can combine with Zn (II).
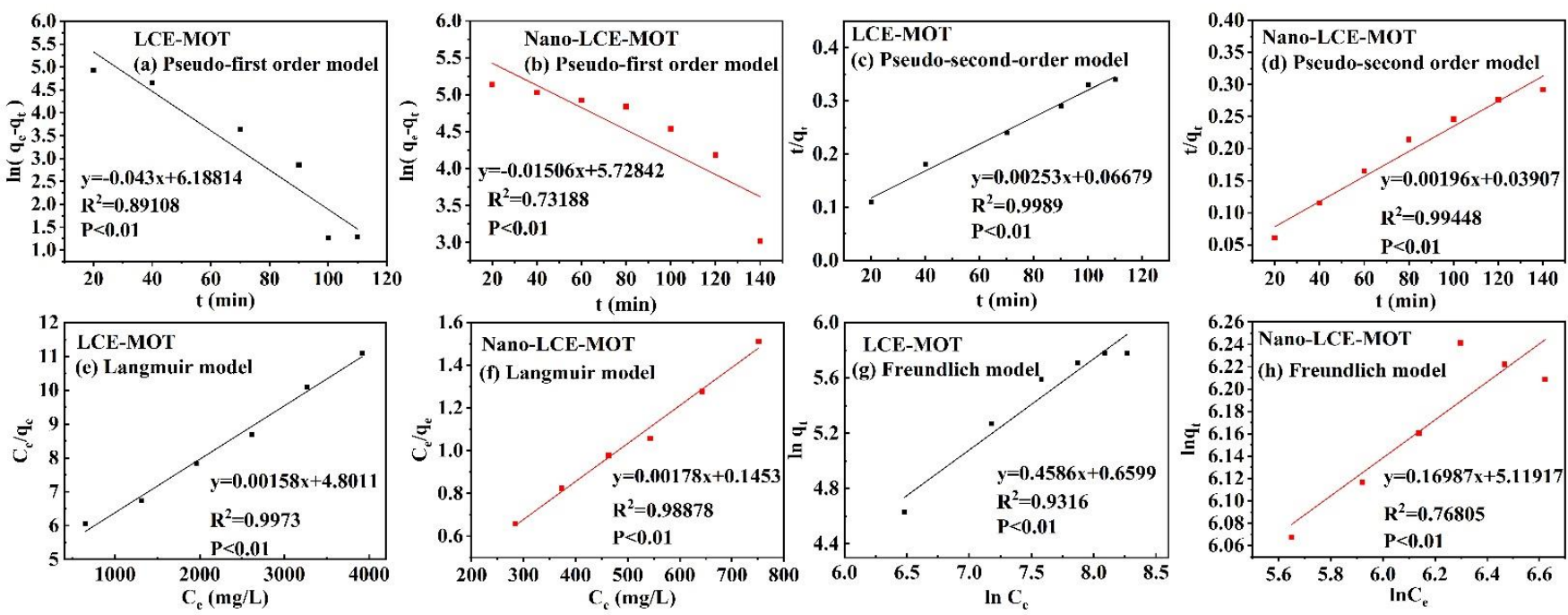

Figure 6. (a-d) Adsorption kinetics equation fitting curves of the experimental data. (e) The Langmuir; (g) Freundlich; models for the adsorption of $\mathrm{Zn}$ (II) ions by LCE-MOT. (f) The Langmuir; (h) Freundlich; models for the adsorption of Zn (II) ions by Nano-LCE-MOT. 
Table 2. $\mathrm{R}^{2}$ and constant values for the different adsorption kinetics models of $\mathrm{Zn}$ (II) for Nano-LCE-MOT and LCE-MOT.

\begin{tabular}{|c|c|c|c|c|c|}
\hline Materials & Parameters & \multicolumn{2}{|c|}{ Pseudo-First Order } & \multicolumn{2}{|c|}{ Pseudo-Second Order } \\
\hline \multirow{3}{*}{ LCE-MOT } & $\mathrm{R}^{2}$ & \multicolumn{2}{|c|}{0.8912} & \multicolumn{2}{|c|}{0.9989} \\
\hline & \multirow{2}{*}{ Constants } & $\mathrm{k}_{1}$ & $0.0045 \min ^{-1}$ & $\mathrm{k}_{2}$ & $0.2876 \mathrm{~min}^{-1}$ \\
\hline & & $\mathrm{q}_{\mathrm{e}}$ & $297.01 \mathrm{mg} / \mathrm{g}$ & $\mathrm{q}_{\mathrm{e}}$ & $327.11 \mathrm{mg} / \mathrm{g}$ \\
\hline \multirow{3}{*}{ Nano-LCE-MOT } & $R^{2}$ & \multicolumn{2}{|c|}{0.7319} & \multicolumn{2}{|c|}{0.9945} \\
\hline & \multirow{2}{*}{ Constants } & $\mathrm{k}_{1}$ & $0.015 \mathrm{~min}^{-1}$ & $\mathrm{k}_{2}$ & $0.000098 \mathrm{~min}^{-1}$ \\
\hline & & $\mathrm{q}_{\mathrm{e}}$ & $541.10 \mathrm{mg} / \mathrm{g}$ & $\mathrm{q}_{\mathrm{e}}$ & $510.20 \mathrm{mg} / \mathrm{g}$ \\
\hline
\end{tabular}

\subsubsection{Adsorption Modelling}

To better understand the ion adsorption processes that occur on nano-LCE-MOT and LCE-MOT, the Langmuir (Equation (5)) and Freundlich (Equation (6)) isotherms were applied to fit the adsorption equilibrium data obtained from the batch adsorption experiments. Figure $6 \mathrm{e}-\mathrm{h}$ shows the fitting of the data to the isotherms, and the correlation coefficient values, among other parameters, are presented in Table 3. From the results, the Langmuir model was found to be more suitable than the Freundlich model. The Langmuir model makes the assumption that the adsorption in the monolayer of the adsorbent takes place when the adsorbent has a uniform exterior structure, in which the binding sites have identical affinity toward adsorption and there is zero interaction among the adsorbent binding sites. According to the intrinsic features of the Langmuir model, it was revealed that the adsorption of Zn (II) by nano-LCE-MOT and LCE-MOT was confined to the monolayers created between the adsorbents and heavy metals, with zero additional same-plane interactions on the surface of the adsorbent by the adsorbate, in a multilayer coverage fashion [52]. The maximum theoretical adsorption capacities of nano-LCE-MOT and LCE-MOT at their optimal temperatures were found to be 326.08 and $561.80 \mathrm{mg} / \mathrm{g}$, respectively, as shown in Table 3. Meanwhile, as also shown in Table 3, compared with the previously reported adsorbents, nano-LCE-MOT and LCE-MOT exhibit higher adsorption capacity toward Zn (II), which illustrates that nano-LCE-MOT and LCEMOT are excellent adsorbents for the adsorption of $\mathrm{Zn}$ (II) from aqueous media. However, maximum adsorption capacity of nano-LCE-MOT is higher than that of LCE-MOT, which proves that the nanosizing treatment tends to improve the intercalation reaction effect and enhance the adsorption capacity of the material. It was further proved that chemisorption affects the adsorption process:

$$
\begin{aligned}
& \frac{\mathrm{C}_{\mathrm{e}}}{\mathrm{q}_{\mathrm{e}}}=\frac{1}{\mathrm{~K}_{\mathrm{L}} \mathrm{q}_{\max }}+\frac{\mathrm{C}_{\mathrm{e}}}{\mathrm{q}_{\max }} \\
& \ln \mathrm{q}_{\mathrm{e}}=\ln \mathrm{K}_{\mathrm{f}}+\frac{1}{\mathrm{n}} \ln \mathrm{C}_{\mathrm{e}}
\end{aligned}
$$

where $\mathrm{K}_{\mathrm{L}}(\mathrm{L} / \mathrm{mg})$ is the Langmuir constant related to the adsorption capacity; $\mathrm{q}_{\max }(\mathrm{mg} / \mathrm{g}$ ) is the monolayer saturation adsorption capacity; $1 / \mathrm{n}$ is the value used to indicate the heterogeneity of the interface; $\mathrm{K}_{\mathrm{f}}$ is the Freundlich constant, and $\mathrm{Ce}(\mathrm{mg} / \mathrm{L})$ is the concentration of metal ions at equilibrium. 
Table 3. $\mathrm{R}^{2}$ and constant values for the different adsorption isotherm models of $\mathrm{Zn}$ (II) for Nano-LCE-MOT and LCE-MOT.

\begin{tabular}{|c|c|c|c|c|c|}
\hline \multirow[b]{3}{*}{ LCE-MOT } & Parameters & \multicolumn{2}{|c|}{ Langmuir } & \multicolumn{2}{|c|}{ Freundlich } \\
\hline & $\mathrm{R}^{2}$ & \multicolumn{2}{|c|}{0.9973} & \multicolumn{2}{|c|}{0.9316} \\
\hline & Constants & $\begin{array}{c}\mathrm{K}_{\mathrm{L}} \\
\mathrm{q}_{\mathrm{max}}\end{array}$ & $\begin{array}{l}0.0311 \mathrm{~L} / \mathrm{mg} \\
326.08 \mathrm{mg} / \mathrm{g}\end{array}$ & $\begin{array}{c}\mathrm{K}_{\mathrm{f}} \\
1 / \mathrm{n}\end{array}$ & $\begin{array}{c}69.11 \mathrm{~L} / \mathrm{mg} \\
0.135\end{array}$ \\
\hline \multirow[b]{2}{*}{ Nano-LCE-MOT } & $\mathrm{R}^{2}$ & \multicolumn{2}{|c|}{0.9888} & \multicolumn{2}{|c|}{0.7681} \\
\hline & Constants & $\begin{array}{c}\mathrm{K}_{\mathrm{L}} \\
\mathrm{q}_{\max }\end{array}$ & $\begin{array}{l}0.0012 \mathrm{~L} / \mathrm{mg} \\
561.80 \mathrm{mg} / \mathrm{g}\end{array}$ & $\begin{array}{c}K_{f} \\
1 / n\end{array}$ & $\begin{array}{c}167.28 \mathrm{~L} / \mathrm{mg} \\
0.1699\end{array}$ \\
\hline
\end{tabular}

\subsection{Desorption and Regeneration Studies}

\subsubsection{Effects of Various Desorption Reagents}

The desorption capacities of nano-LCE-MOT and LCE-MOT were investigated using $\mathrm{HCl}, \mathrm{HNO}_{3}$ and $\mathrm{H}_{2} \mathrm{SO}_{4}$ as proton exchange desorption reagents and $\mathrm{NaOH}$ as a chelating desorption reagent to regenerate the materials. Figure $7 \mathrm{a}, \mathrm{b}$ show the effects of the different desorption reagents on the desorption capacity of nano-LCE-MOT and LCE-MOT. It can be seen from the results of the desorption experiments that both the desorption processes of $\mathrm{Zn}$ (II) from Zn (II)-loaded nano-LCE-MOT and Zn (II)-loaded LCE-MOT were higher using $\mathrm{HCl}$ than the other desorption reagents. Hence, the desorption of $\mathrm{Zn}$ (II) from nano-LCEMOT and LCE-MOT was performed using $\mathrm{HCl}$ in the subsequent regeneration experiments.
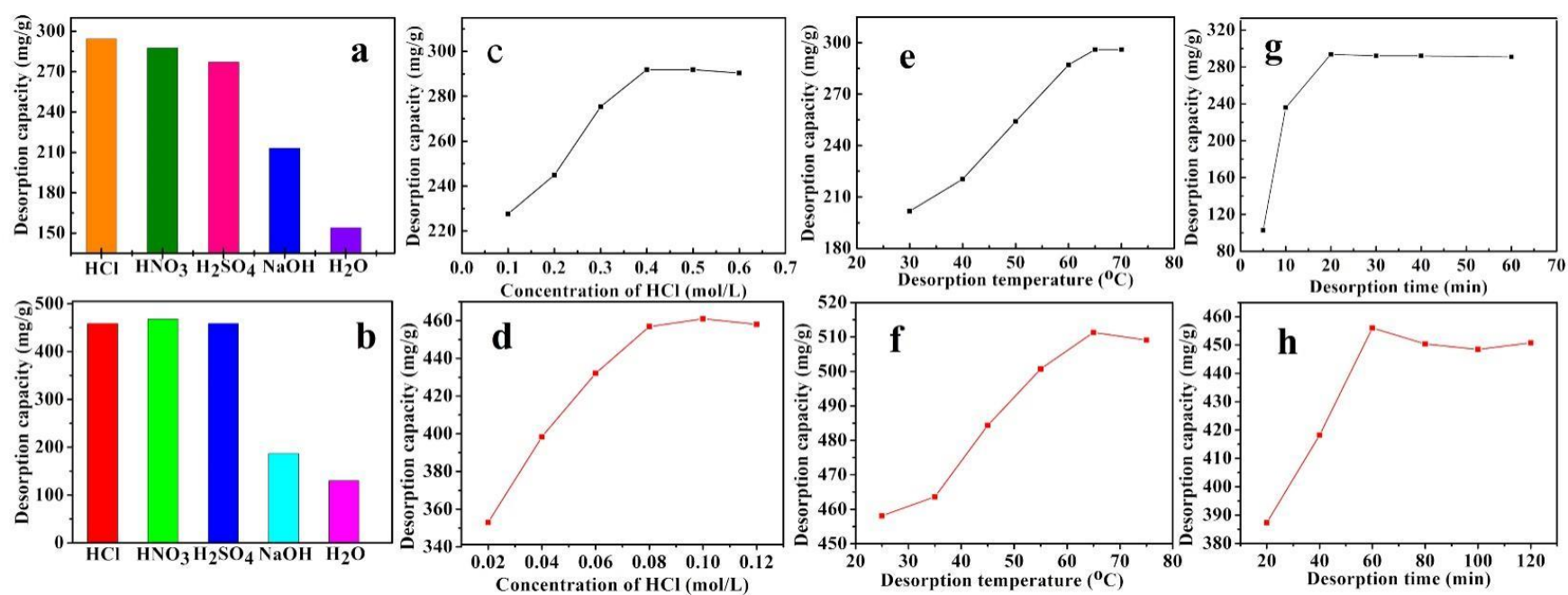

Figure 7. Effects of various desorption reagents on desorption capacity of LCE-MOT (a) and Nano-LCE-MOT (b). Effects of desorption agents' concentration on desorption capacity of LCE-MOT (c) and Nano-LCE-MOT (d). Effects of desorption temperature on desorption capacity of LCE-MOT (e) and Nano-LCE-MOT (f). Effects of desorption time on desorption capacity of LCE-MOT (g) and Nano-LCE-MOT (h).

\subsubsection{Effects of Desorption Agent Concentration}

The desorption capacity was found to be related to the concentration of the desorption regents. As show in Figure $7 \mathrm{c}, \mathrm{d}$, the effects that different concentrations of $\mathrm{HCl}$ have on the desorption of Zn (II)-loaded nano-LCE-MOT and Zn (II)-loaded LCE-MOT were investigated. It can be seen from the data that the desorption capacity increases in line with an increase in the concentration of $\mathrm{HCl}$ until the system reaches desorption equilibrium. Also, the desorption capacity of nano-LCE-MOT was found to be higher than that of LCEMOT and that maximum desorption of Zn (II)-loaded nano-LCE-MOT could therefore be reached using a lower concentration of $\mathrm{HCl}$. The results of the experiments infer that as the proton $\left(\mathrm{H}^{+}\right)$concentration is lower at a lower concentration of $\mathrm{HCl}$, the $\mathrm{H}^{+}$are completely replaced, resulting in nano-LCE-MOT and LCE-MOT losing their absorbability. While, in the presence of a high concentration of $\mathrm{H}^{+}$the adsorbents are protonated, which means 
that the adsorption site for $\mathrm{Zn}$ (II) are occupied by $\mathrm{H}^{+}$, meaning that there are no increases in the desorption capacities of Zn (II)-loaded nano-LCE-MOT and Zn (II)-loaded LCE-MOT. The maximum desorption values of $\mathrm{Zn}$ (II)-loaded nano-LCE-MOT and Zn (II)-loaded LCE-MOT reached 456.81 and $291.88 \mathrm{mg} / \mathrm{g}$ for $\mathrm{Zn}$ (II) at $\mathrm{HCl}$ concentrations of 0.08 and $0.4 \mathrm{~mol} / \mathrm{L}$, respectively.

\subsubsection{Effects of Desorption Temperature}

As shown in Figure 7e,f, the desorption capacities of the absorbents increased in line with the temperature, which might be a result of more $\mathrm{H}+$ ion activity at higher temperature, meaning that the $\mathrm{H}+$ compete with $\mathrm{Zn}$ (II) on the surface of $\mathrm{Zn}$ (II)-loaded nano-LCE-MOT and Zn (II)-loaded LCE-MOT, thus leading to an increase in the desorption rate. While, upon a further increase in the temperature, the active sites might be destroyed if the temperature is too high [53], hence leading to a slight decrease in the desorption capacities of Zn (II)-loaded nano-LCE-MOT and Zn (II)-loaded LCE-MOT.

\subsubsection{Effects of Desorption Time}

As shown in Figure $7 \mathrm{~g}$, $\mathrm{h}$, the best desorption times of nano-LCE-MOT and LCE-MOT were 60 and $20 \mathrm{~min}$, respectively. With an increase in the desorption time, the desorption capacity first increased and then decreased. In the initial stage of desorption, $\mathrm{H}+$ gradually replaces the $\mathrm{Zn}$ (II) adsorbed on the material, therefore meaning that there is a gradual increase in the adsorption capacity. After a certain adsorption time, the material continues to adsorb $\mathrm{Zn}$ (II), so as to reach adsorption-desorption equilibrium.

\subsubsection{Regeneration and Reuse}

The recovery of heavy metals adsorbed on the nano-LCE-MOT and LCE-MOT surfaces is of great significance toward improving the economy of nano-LCE-MOT and LCE-MOT. Table 4 shows the data on the reusability of nano-LCE-MOT and LCE-MOT investigated over three adsorption/desorption cycles. The adsorption capacities of nano-LCE-MOT and LCE-MOT were observed to decrease gradually with the number of cycles, which might be because the adsorption sites on the surfaces of nano-LCE-MOT and LCE-MOT were destroyed at low $\mathrm{pH}$ during the regeneration cycles. The results show that nano-LCE-MOT could be recycled up to three times for the adsorption of $\mathrm{Zn}$ (II) with very little loss in efficiency, while LCE-MOT could be recycled twice, proving that the nanosizing treatment enhances the reusability of the adsorbent.

Table 4. Adsorption/desorption cycles for Zn (II) onto Nano-LCE-MOT and LCE-MOT.

\begin{tabular}{ccccc}
\hline \multirow{2}{*}{ Materials } & Adsorption-Desorption Capacity & \multicolumn{3}{c}{ Adsorption/Desorption Cycles } \\
\cline { 3 - 5 } & & $\mathbf{1}$ & $\mathbf{2}$ & $\mathbf{3}$ \\
\hline \multirow{2}{*}{ LCE-MOT } & Adsorption capacity & $324.02 \mathrm{mg} / \mathrm{g}$ & $317.05 \mathrm{mg} / \mathrm{g}$ & $280.23 \mathrm{mg} / \mathrm{g}$ \\
& Desorption capacity & $296.11 \mathrm{mg} / \mathrm{g}$ & $267.11 \mathrm{mg} / \mathrm{g}$ & $145.37 \mathrm{mg} / \mathrm{g}$ \\
\hline \multirow{2}{*}{ Nano-LCE-MOT } & Adsorption capacity & $520.33 \mathrm{mg} / \mathrm{g}$ & $503.73 \mathrm{mg} / \mathrm{g}$ & $497.54 \mathrm{mg} / \mathrm{g}$ \\
& Desorption capacity & $507.29 \mathrm{mg} / \mathrm{g}$ & $497.38 \mathrm{mg} / \mathrm{g}$ & $490.63 \mathrm{mg} / \mathrm{g}$ \\
\hline
\end{tabular}

3.3.6. Adsorption Capacity of Lignocellulose-Based Materials to Zn (II)

Table 5 lists four lignocellulose-based adsorbents for comparison with this article. It can be seen from the table that nano-LCE-MOT has a good adsorption effect on $\mathrm{Zn}$ (II). It can be concluded that the material can be used to adsorb Zn (II). 
Table 5. Comparison of adsorption properties of different materials for $\mathrm{Zn}$ (II).

\begin{tabular}{ccc}
\hline Sample & Zn (II) (mg/g) & Author \\
\hline nano-LCE-MOT & 520.33 & This work \\
Smectite clay & 357.29 & Zhang [37] \\
Sdiri [38] \\
Thiol-lignocellulose sodium bentonite nanocomposites & 102.04 & Diab [39] \\
Sulfhydryl-modified cassava straw & 49.75 & Deng [54] \\
Lignocellulose@ activated clay nanocomposite & 60.24 & Zhang [55] \\
Functionalized lignocellulose derived from waste biomass & 315.90 & Dang [56] \\
Biochars derived from long-root Eichhornia crassipes & 45.49 & Li [57] \\
\hline
\end{tabular}

\section{Discussion}

The adsorption mechanism of $\mathrm{Zn}$ (II) on nano-LCE-MOT and LCE-MOT was clarified by FTIR spectroscopy, TGA, SEM, TEM and EDX-mapping analysis. As shown in the FTIR spectra in Figure 8i, nano-LCE-MOT and LCE-MOT exhibit peaks at 3438 and $3468 \mathrm{~cm}^{-1}$, respectively, which can be attributed to the - $\mathrm{O}-\mathrm{H}$ stretching of the hydroxyl groups. As shown in the data, after adsorption, these peaks shifted to lower wavenumber values of 3374 and $3349 \mathrm{~cm}^{-1}$ respectively, indicating that the -O-H groups of nano-LCE-MOT and LCE-MOT participated in the adsorption process, which in turn demonstrates the involvement of oxygen in the chemisorption of $\mathrm{Zn}$ (II) in the subsequent complexation process. The characteristic absorption peaks at approximately $1690 \mathrm{~cm}^{-1}$ for LCE-MOT and $1646 \mathrm{~cm}^{-1}$ for nano-LCE-MOT can be attributed to $-\mathrm{C}=\mathrm{O}$ stretching in the carboxylic organic acid groups of the materials, which were shifted to lower wavenumber values of 1687 and $1657 \mathrm{~cm}^{-1}$ after adsorption and 1657 and $1643 \mathrm{~cm}^{-1}$ after desorption, respectively, as the possible result of the oxygen in the $-\mathrm{C}=\mathrm{O}$ of nano-LCE-MOT and LCE-MOT forming complexes with the heavy metal ions [58]. The -OH in the carboxylic group exhibited characteristic absorption peaks for nano-LCE-MOT and LCE-MOT at 1464 and $1456 \mathrm{~cm}^{-1}$, respectively, which disappeared after adsorption, proving that the $-\mathrm{C}=\mathrm{O}$ bonds in the carboxylic organic acid groups participate in the chemisorption process. These changes in the absorption peaks indicate that the activated sites on the surfaces of nano-LCE-MOT and LCE-MOT contain hydroxyl and carboxylic functional groups, which form new chemical bonds with Zn (II), resulting in some of the peaks shifting and disappearing. Furthermore, although ion exchange and electrostatic attraction may also occur during the adsorption process chemical adsorption is the main adsorption process.

From the TGA results, as the $\mathrm{Zn}$ (II) ions are adsorbed on the surfaces of nano-LCEMOT and LCE-MOT, this has an impact on the weight loss of the adsorbents. The mass loss rate of the nanosizing treated nano-LCE-MOT was higher than that of LCE-MOT, proving that that nanosizing treatment leads to the adsorbent more readily undergoing thermal decomposition. As shown in Figure $8 \mathrm{j}$ in the TGA curves of nano-LCE-MOT with adsorbed Zn (II) and LCE-MOT with adsorbed Zn (II), the weight loss ratios of the adsorbents changed when they were loaded with Zn (II) ions. This indicates that Zn (II) strongly adsorbs onto nano-LCE-MOT and LCE-MOT, therefore contributing toward their loss in weight. The experimental results prove that the adsorption processes of $\mathrm{Zn}$ (II) on nano-LCE-MOT and LCE-MOT are both physical and chemical in nature, which might be due to the interaction between the oxygen-containing functional groups on the adsorbent surface and Zn (II) taking place via a complexation mechanism [59].

Figure 8a-h show the SEM and TEM images of nano-LCE-MOT and LCE-MOT after the adsorption and desorption of $\mathrm{Zn}$ (II). It can be seen from Figure $8 \mathrm{a}-\mathrm{h}$ that the layered structures of the surfaces of the adsorbents disappear after Zn (II) adsorption, with the appearance of a lot of granular matter on their surface. This indicates that Zn (II) adsorbs at the adsorption sites and pores of the materials, with the materials regaining loose layered structures and pores after Zn (II) desorption [60]. 

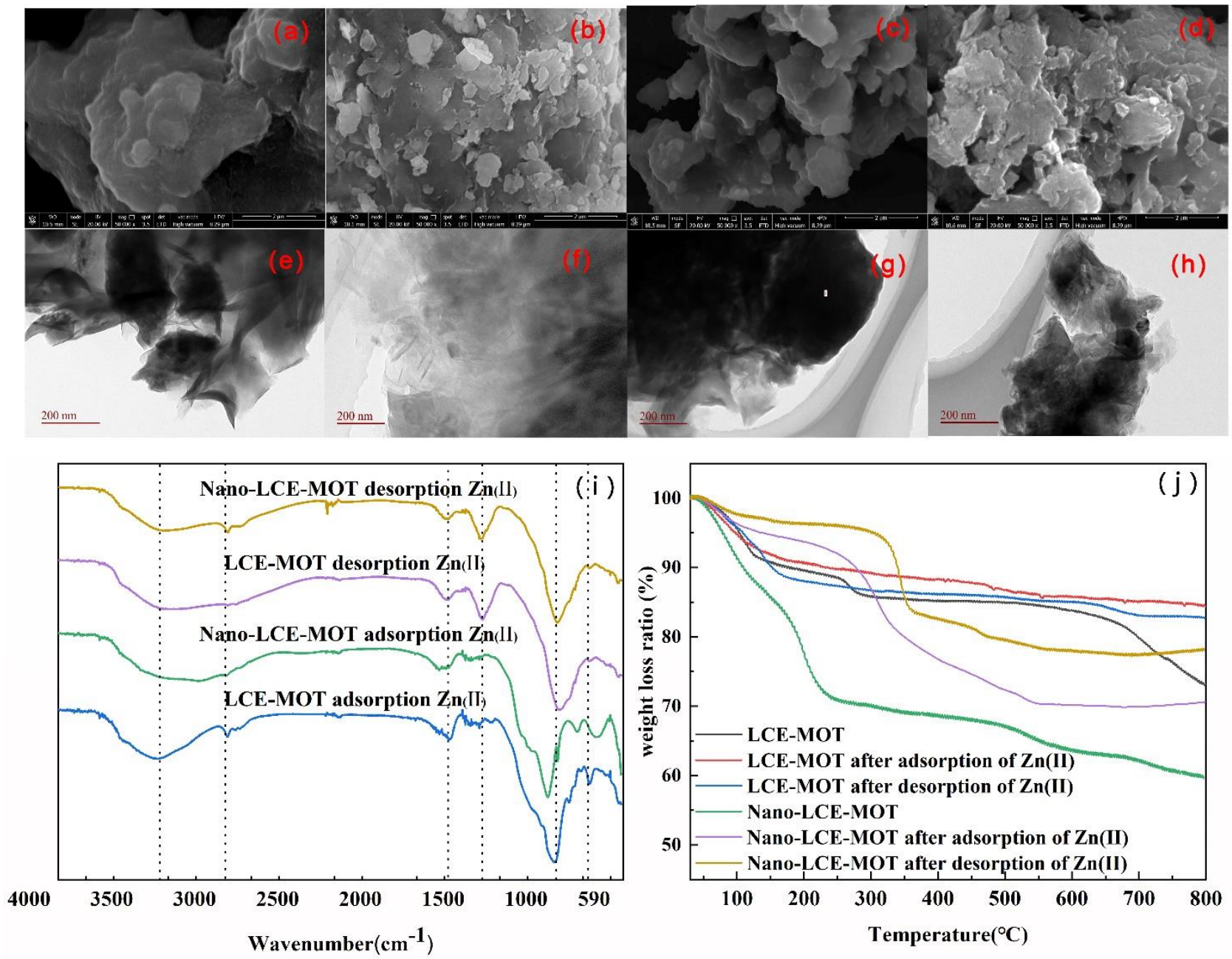

Figure 8. SEM of LCE-MOT after adsorption (a) and desorption (b) of Zn (II). SEM of Nano-LCE-MOT after adsorption (c) and desorption (d) of Zn (II). TEM of LCE-MOT after adsorption (e) and desorption (f) of Zn (II). TEM of Nano-LCE-MOT after adsorption (g) and desorption (h) of Zn (II). (i) FTIR of Nano-LCE-MOT and LCE-MOT adsorption and desorption Zn (II). (j) TG of Nano-LCE-MOT and LCE-MOT adsorption and desorption Zn (II).

From the EDX data in Figure $9 \mathrm{a}-\mathrm{f}$, it can be seen that there are only four elements, $\mathrm{C}, \mathrm{O}, \mathrm{Si}$ and $\mathrm{Al}$, present in nano-LCE-MOT and LCE-MOT. After the adsorption of $\mathrm{Zn}$ (II), the peak for Zn (II) is present in the EDX data, and the intensity of the absorption peak of oxygen decreases. From the mapping diagram, it can be seen that the $\mathrm{Zn}$ (II) is uniformly distributed on both the LCE-MOT and the nano-LCE-MOT surfaces, with more $\mathrm{Zn}$ (II) being obviously distributed on nano-LCE-MOT than on LCE-MOT. Therefore, this means that the adsorption capacity of nano-LCE-MOT toward Zn (II) is higher than that of LCE-MOT. After desorption, the Zn (II) on the surface of the materials is desorbed, and only the signals of the original elements can be once again observed in the EDX data. The oxygen peaks returns to its original intensity, with no signal for Zn (II) observed in the mapping data, which indicates that Zn (II) is completely desorbed, and that oxygen participates in the adsorption process. 

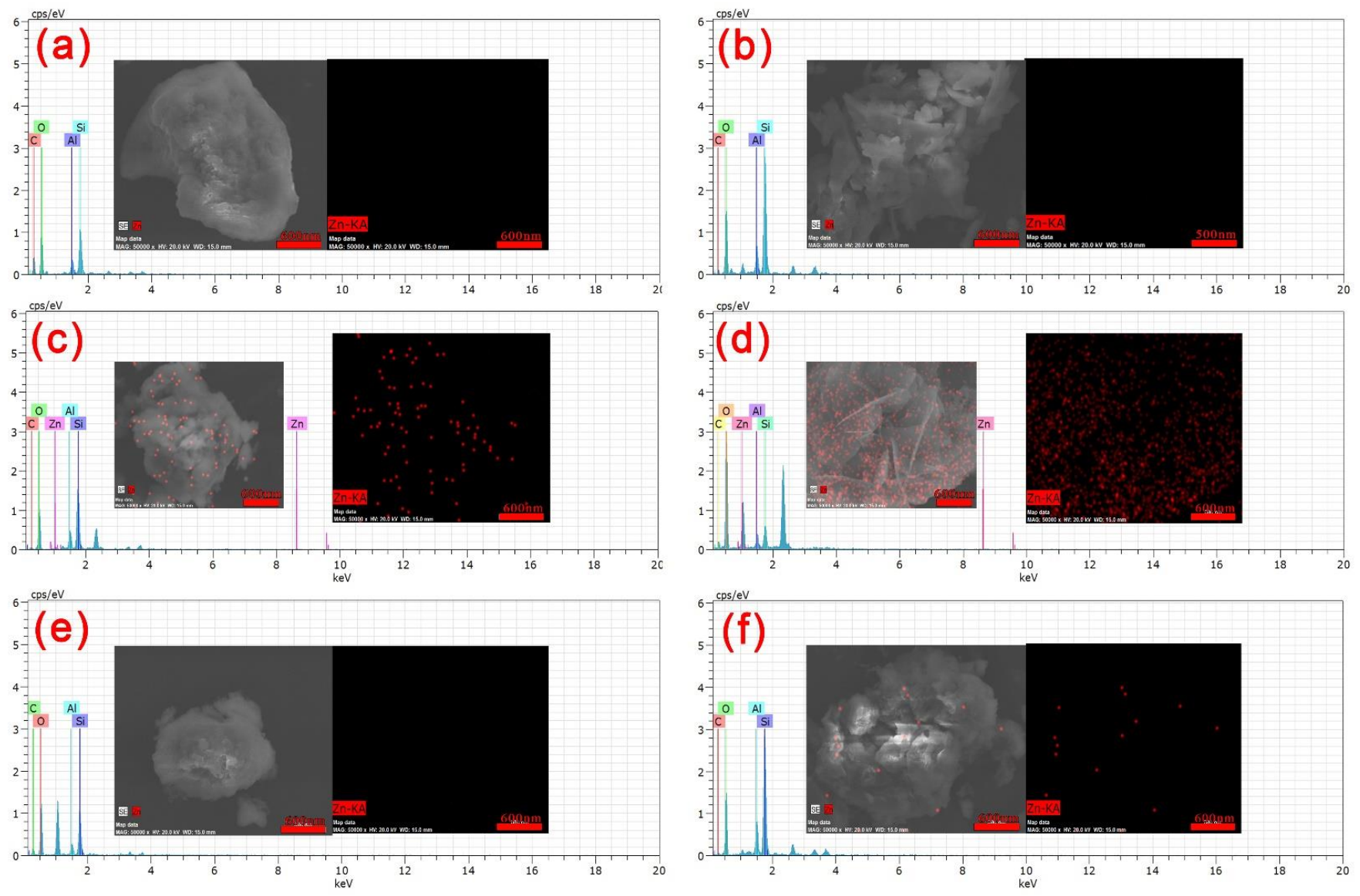

Figure 9. EDX and mapping of LCE-MOT (a), LCE-MOT adsorption (c) and desorption (e) Zn (II).EDX and mapping of Nano-LCE-MOT (b), Nano-LCE-MOT adsorption (d) and desorption (f) Zn (II).

\section{Conclusions}

In this study, it was shown that LCE/MOT and nano-LCE/MOT can be used to effectively extract Zn (II) from aqueous solution, with the adsorption capacity toward $\mathrm{Zn}$ (II) of nano-LCE/MOT being higher than that of LCE/MOT, reaching $513.48 \mathrm{mg} / \mathrm{g}$. The optimal adsorption of $\mathrm{Zn}$ (II) on nano-LCE/MOT occurs at $\mathrm{pH} 4.52$, at $60{ }^{\circ} \mathrm{C}$, with a contact time of $160 \mathrm{~min}$. The optimal adsorption of $\mathrm{Zn}$ (II) on LCE/MOT occurs at $\mathrm{pH}$ 5.3 , at $50{ }^{\circ} \mathrm{C}$, with a contact time of $100 \mathrm{~min}$. Among the evaluated kinetic models and isotherms, the pseudo-second-order adsorption kinetics equation and Langmuir isothermal adsorption model gave the best fit for the $\mathrm{Zn}$ (II) adsorption process, suggesting that the adsorption process mainly occurs via monolayer chemical adsorption. Desorption and regeneration experiments revealed that $\mathrm{HCl}$ eluted $456.81 \mathrm{mg} / \mathrm{g}$ of $\mathrm{Zn}$ (II) from Zn-loaded nano-LCE/MOT and $291.88 \mathrm{mg} / \mathrm{g}$ of Zn (II) from Zn-loaded LCE/MOT. Overall, these results suggest that nano-LCE/MOT is an excellent adsorbent for the extraction of $\mathrm{Zn}$ (II) from aqueous media.

Author Contributions: Writing—original draft, W.Z. and Y.A.; investigation H.L. and B.W.; methodology, Z.C. and Y.R.; formal analysis, Y.Z.; data curation, Y.S. and Z.H.; writing-review and editing, X.Z.; Resources, S.W.; supervision, X.W. All authors have read and agreed to the published version of the manuscript.

Funding: This research was funded by Natural Science Foundation of Inner Mongolia, grant number 2020MS02007, the High-Level Talent Research Initiation Project of Inner Mongolia Agricultural University, grant number NDYB2018-59, Science and Technology Achievements Transformation Project of Inner Mongolia Autonomous Region in China, grant number CGZH2018136, and Grass Talents Engineering Youth Innovation and Entrepreneurship of Inner Mongolia Autonomous Region 
in China grant number Q2017053,Inner Mongolia Autonomous Region Postgraduate Research and Innovation Funding Project,BZ2020055.

Institutional Review Board Statement: Not applicable.

Informed Consent Statement: Not applicable.

Data Availability Statement: The data presented in this study are available on request from the corresponding author.

Acknowledgments: The experimental part of this work was supported by Inner Mongolia Key Laboratory of Sandy Shrubs Fibrosis and Energy Development and Utilization.

Conflicts of Interest: The authors declare that there is no conflict of interests regarding the publication of this paper.

\section{References}

1. Volesky, B.; Holan, Z.R. Biosorption of heavy metals. Biotechnol. Prog. 1995, 11, 235-250. [CrossRef]

2. Wang, J.; Chen, C. Biosorbents for heavy metals removal and their future. Biotechnol. Adv. 2009, 27, 195-226. [CrossRef] [PubMed]

3. Bano, A.; Hussain, J.; Akbar, A.; Mehmood, K.; Anwar, M.; Hasni, M.S.; Ullah, S.; Sajid, S.; Ali, I. Biosorption of heavy metals by obligate halophilic fungi. Chemosphere 2018, 199, 218-222. [CrossRef]

4. Mohan, D.; Singh, K.P. Single- and multi-component adsorption of cadmium and zinc using activated carbon derived from bagasse-an agricultural waste. Water Res. 2002, 36, 2304-2318. [CrossRef]

5. Kongsricharoern, N.; Polprasert, C. Chromium removal by a bipolar electro-chemical precipitation process. Water Sci. Technol. 1996, 34, 109-116. [CrossRef]

6. Zhang, Z.; Zheng, H.; Sun, Y.; Zhao, C.; Zhou, Y.; Tang, X.; Zhao, C. A combined process of chemical precipitation and flocculation for treating phosphating wastewater. Desalination Water Treat. 2016, 57, 25520-25531. [CrossRef]

7. Chukwu, U.J.; Uzoukwu, B.A. Synergistic extraction of Zn2+ from aqueous buffer medium of chloride ions into 1- Phenyl -3Methyl -4- trichloro acetyl pyrazolone -5 in benzene and hexane. Recent Patents Mater. Sci. 2010, 3, 2. [CrossRef]

8. Tang, W.; Zeng, G.; Gong, J.; Liang, J.; Xu, P.; Zhang, C.; Huang, B. Impact of humic/fulvic acid on the removal of heavy metals from aqueous solutions using nanomaterials: A review. Sci. Total Environ. 2014, 468, 1014-1027. [CrossRef] [PubMed]

9. Cherif, A.T.; Elmidaoui, A.; Gavach, C. Separation of $\mathrm{Ag}^{+}, \mathrm{Zn}^{2+}$ and $\mathrm{Cu}^{2+}$ ions by electrodialysis with monovalent cation specific membrane and EDTA. J. Membr. Sci. 1993, 76, 39-49. [CrossRef]

10. Cherif, A.T.; Gavach, C.; Molenat, J.; Elmidaoui, A. Transport and separation of $\mathrm{Ag}^{+}$and $\mathrm{Zn}^{2+}$ by donnan dialysis through a monovalent cation selective membrane. Talanta 1998, 46, 1605-1611. [CrossRef]

11. Pociecha, M.; Kastelec, D.; Lestan, D. Electrochemical EDTA recycling after soil washing of Pb, Zn and Cd contaminated soil. J. Hazard. Mater. 2011, 192, 714-721. [CrossRef] [PubMed]

12. Ipek, U. Removal of Ni (II) and Zn (II) from an aqueous solutionby reverse osmosis. Desalination 2005, 174, 161-169. [CrossRef]

13. Ujang, Z.; Anderson, G.K. Application of low-pressure reverse osmosis membrane for $\mathrm{Zn}^{2+}$ and $\mathrm{Cu}^{2}+$ removal from wastewater. Water Sci. Technol. 1996, 34, 247-253. [CrossRef]

14. Franco, P.E.; Veit, M.T.; Borba, C.E.; da Cunha Gonçalves, G.; Fagundes-Klen, M.R.; Bergamasco, R.; da Silva, E.A.; Suzaki, P.Y.R. Nickel (II) and zinc (II) removal using Amberlite IR-120 resin: Ion exchange equilibrium and kinetics. Chem. Eng. J. 2013, 221, 426-435. [CrossRef]

15. Ostroski, I.C.; Barros, M.A.S.D.; Silva, E.A.; Dantas, J.H.; Arroyo, P.A.; Lima, O.C.M. A comparative study for the ion exchange of Fe (III) and Zn (II) on zeolite NaY. J. Hazard. Mater. 2009, 161, 1404-1412. [CrossRef] [PubMed]

16. Bhattacharya, A.K.; Mandal, S.N.; Das, S.K. Adsorption of Zn (II) from aqueous solution by using different adsorbents. Chem. Eng. J. 2006, 123, 43-51. [CrossRef]

17. Bereket, G.; Arog, A.Z.; Özel, M.Z. Removal of Pb (II), Cd (II), Cu (II), and Zn (II) from Aqueous Solutions by Adsorption on Bentonite. J. Colloid Interface Sci. 1997, 187, 338-343. [CrossRef] [PubMed]

18. Kubilay, Ş.; Gürkan, R.; Savran, A.; Şahan, T. Removal of Cu (II), Zn (II) and Co (II) ions from aqueous solutions by adsorption onto natural bentonite. Adsorption 2007, 13, 41-51. [CrossRef]

19. Juang, R.; Shao, H. Effect of $\mathrm{pH}$ on competitive adsorption of $\mathrm{Cu}(\mathrm{II}), \mathrm{Ni}(\mathrm{II})$, and $\mathrm{Zn}$ (II) from water onto chitosan beads. Adsorption 2002, 8, 71-78. [CrossRef]

20. Pranata Putra, W.; Kamari, A.; Najiah Mohd Yusoff, S.; Fauziah Ishak, C.; Mohamed, A.; Hashim, N.; Md Isa, I. Biosorption of Cu (II), $\mathrm{Pb}$ (II) and $\mathrm{Zn}$ (II) ions from aqueous solutions using selected waste materials: Adsorption and characterisation studies. J. Encapsulation Adsorpt. Sci. 2014, 4, 25-35. [CrossRef]

21. Hoseinian, F.S.; Irannajad, M.; Nooshabadi, A.J. Ion flotation for removal of Ni (II) and Zn (II) ions from wastewaters. Int. J. Miner. Process. 2015, 143, 131-137. [CrossRef]

22. Matarese Palmieri, R.; Pera, L.L.; Di Bella, G.; Dugo, G. Simultaneous determination of Cd (II), Cu (II), Pb (II) and Zn (II) by derivative stripping chronopotentiometry in Pittosporum tobira leaves: A measurement of local atmospheric pollution in Messina (Sicily, Italy). Chemosphere 2005, 59, 1161-1168. [CrossRef] 
23. Pang, F.M.; Kumar, P.; Teng, T.T.; Mohd Omar, A.K.; Wasewar, K.L. Removal of lead, zinc and iron by coagulation-flocculation. J. Taiwan Inst. Chem. Eng. 2011, 42, 809-815. [CrossRef]

24. Alvarez, M.T.; Crespo, C.; Mattiasson, B. Precipitation of $\mathrm{Zn}$ (II), $\mathrm{Cu}$ (II) and $\mathrm{Pb}$ (II) at bench-scale using biogenic hydrogen sulfide from the utilization of volatile fatty acids. Chemosphere 2007, 66, 1677-1683. [CrossRef]

25. Trainor, T.P.; Brown, G.E.; Parks, G.A. Adsorption and precipitation of aqueous Zn (II) on alumina powders. J. Colloid Interface Sci. 2000, 231, 359-372. [CrossRef] [PubMed]

26. Guan, B.; Ni, W.; Wu, Z.; Lai, Y. Removal of Mn (II) and Zn (II) ions from flue gas desulfurization wastewater with water-soluble chitosan. Sep. Purif. Technol. 2009, 65, 269-274. [CrossRef]

27. Alqadami, A.A.; Naushad, M.; Abdalla, M.A.; Ahamad, T.; Abdullah Alothman, Z.; Alshehri, S.M. Synthesis and characterization of $\mathrm{Fe}_{3} \mathrm{O}_{4} @ \mathrm{TSC}$ nanocomposite: Highly efficient removal of toxic metal ions from aqueous medium. RSC Adv. 2016, 6, 22679-22689. [CrossRef]

28. Li, S.; Song, X. Study on the preparation and production factors of a direct lignocellulose biomass fuel cell. J. Electroanal. Chem. 2018, 810, 55-61. [CrossRef]

29. Guerra, A.; Filpponen, I.; Lucia, L.A.; Argyropoulos, D.S. Comparative Evaluation of three lignin isolation protocols for various wood species. J. Agric. Food Chem. 2006, 54, 9696-9705. [CrossRef]

30. Doherty, W.O.S.; Mousavioun, P.; Fellows, C.M. Value-adding to cellulosic ethanol: Lignin polymers. Ind. Crop. Prod. 2011, 33, 259-276. [CrossRef]

31. Saha, P.; Manna, S.; Chowdhury, S.R.; Sen, R.; Roy, D.; Adhikari, B. Enhancement of tensile strength of lignocellulosic jute fibers by alkali-steam treatment. Bioresour. Technol. 2010, 101, 3182-3187. [CrossRef]

32. Mak, K.F.; Lee, C.; Hone, J.; Shan, J.; Heinz, T.F. Atomically ThinMoS 2 : A new direct-gap semiconductor. Phys. Rev. Lett. 2010, 105, 136805. [CrossRef]

33. Uetani, K.; Yano, H. Nano fibrillation of Wood Pulp Using a High-Speed Blender. Biomacromolecules 2010, 12, 348-353. [CrossRef]

34. Malainine, M.E.; Mahrouz, M.; Dufresne, A. Thermoplastic nanocomposites based on cellulose microfibrils from Opuntia Ficus-indica parenchyma cell. Compos. Sci. Technol. 2005, 65, 1520-1526. [CrossRef]

35. Sinha Ray, S.; Okamoto, M. Polymer/layered silicate nanocomposites: A review from preparation to processing. Prog. Polym. Sci. 2003, 28, 1539-1641. [CrossRef]

36. Pavlidou, S.; Papaspyrides, C.D. A review on polymer-layered silicate nanocomposites. Prog. Polym. Sci. 2008, 33, 1119-1198. [CrossRef]

37. Zhang, W.; An, Y.; Li, S.; Liu, Z.; Chen, Z.; Ren, Y.; Wang, S.; Zhang, X.; Wang, X. Enhanced heavy metal removal from an aqueous environment using an eco-friendly and sustainable adsorbent. Sci. Rep. 2020, 10, 16453. [CrossRef] [PubMed]

38. Sdiri, A.T.; Higashi, T.; Jamoussi, F. Adsorption of copper and zinc onto natural clay in single and binary systems. Int. J. Environ. Sci. Technol. 2014, 11, 1081-1092. [CrossRef]

39. Diab, M.A.; Attia, N.F.; Attia, S.; El-Shahat, M.F. Green synthesis of cost-effective and efficient nano adsorbents based on zeroand two-dimensional nanomaterials for $\mathrm{Zn}^{2+}$ and $\mathrm{Cr}^{3+}$ removal from aqueous solutions. Synth. Met. 2020, 265, 116411. [CrossRef]

40. Sing, K.S.W.; Williams, R.T. Physisorption Hysteresis Loops and the Characterization of Nano porous Materials. Adsorpt. Sci. Technol. 2004, 22, 773-782. [CrossRef]

41. Xu, J.K.; Zhou, P.F.; Dai, L.; Gui, Y.; Yuan, L.; Shen, X.J.; Zhang, C.T.; Huo, K.F. A scalable waste-free biorefinery inspires revenue from holistic lignocellulose valorization. Green Chem. 2021, 23, 6008-6019. [CrossRef]

42. Zhang, W.; Duo, H.; Li, S.; An, Y.; Chen, Z.; Liu, Z.; Ren, Y.; Wang, S.; Zhang, X.; Wang, X. An overview of the recent advances in functionalization biomass adsorbents for toxic metals removal. Colloid Interface Sci. Commun. 2020, 38, 100308. [CrossRef]

43. Zhang, X.; Wang, X.; Chen, Z. A novel nanocomposite as an efficient adsorbent for the rapid adsorption of Ni (II) from aqueous solution. Materials 2017, 10, 1124. [CrossRef]

44. An, Y.; Zhang, X.; Wang, X.; Chen, Z.; Wu, X. Nano@lignocellulose intercalated montmorillonite as adsorbent for effective Mn (II) removal from aqueous solution. Sci. Rep. 2018, 8, 10863. [CrossRef]

45. Wang, Y.; Wang, R.; Lin, N.; Wang, Y.; Zhang, X. Highly efficient microwave-assisted Fenton degradation bisphenol A using iron oxide modified double perovskite intercalated montmorillonite composite nanomaterial as catalyst. J. Colloid Interface Sci. 2021, 594, 446-459. [CrossRef]

46. Pei, X.; Gan, L.; Tong, Z.; Gao, H.; Meng, S.; Zhang, W.; Wang, P.; Chen, Y. Robust cellulose-based composite adsorption membrane for heavy metal removal. J. Hazard. Mater. 2020, 406, 124746. [CrossRef]

47. Yousefi, N.; Jones, M.; Bismarck Mautner, A. Fungal chitin-glucan nanopapers with heavy metal adsorption properties for ultrafiltration of organic solvents and water. Carbohydr. Polym. 2020, 253, 117273. [CrossRef] [PubMed]

48. Boughrara, L.; Sebba, F.Z.; Sebti, H.; Choukchou-Braham, E.; Bounaceur, B.; Kada, S.O.; Zaoui, F. Removal of Zn (II) and Ni (II) heavy metal ions by new alginic acid-ester derivatives materials. Carbohydr. Polym. 2021, 272, 118439. [CrossRef] [PubMed]

49. Liu, S.; Xie, Z.; Zhu, Y.; Zhu, Y.; Jiang, Y.; Wang, Y.; Gao, H. Adsorption characteristics of modified rice straw biochar for Zn and in-situ remediation of $\mathrm{Zn}$ contaminated soil. Environ. Technol. Innov. 2021, 22, 101388. [CrossRef]

50. He, X.; Zhang, T.; Xue, Q.; Zhou, Y.; Wang, H.; Bolan, N.S.; Jiang, R.; Tsang, D.C. Enhanced adsorption of Cu (II) and Zn (II) from aqueous solution by polyethyleneimine modified straw hydrochar. Sci. Total Environ. 2021, 778, 146116. [CrossRef] [PubMed] 
51. Ighalo, J.O.; Arowoyele, L.T.; Ogunniyi, S.; Adeyanju, C.A.; Oladipo-Emmanuel, F.M.; Belgore, O.R.; Omisore, M.O.; Adeniyi, A.G. Recent innovations in chemical engineering (formerly recent patents on chemical engineering). Bentham Sci. 2021, 14, 148-159. [CrossRef]

52. Xu, Z.; Lin, Y.; Lin, Y.; Yang, D.; Zheng, H. Adsorption behaviors of paper mill sludge biochar to remove Cu, Zn and As in wastewater. Environ. Technol. Innov. 2021, 23, 101616. [CrossRef]

53. Wang, Z.; Li, T.; Liu, D.; Fu, Q.; Hou, R.; Li, Q.; Cui, S.; Li, M. Research on the adsorption mechanism of Cu and Zn by biochar under freeze-thaw conditions. Sci. Total Environ. 2021, 774, 145194. [CrossRef]

54. Deng, H.; Li, Y.F.; Kang, C.Y.; Yan, L.; Li, S.; Li, S. Adsorption characteristics of Cu (II) and Zn (II) in water on sulfhydryl modified cassava straw. Water Treat. Technol. 2021, 47, 22-27. [CrossRef]

55. Zhang, X.; Hao, Y.; Chen, Z.; An, Y.; Zhang, W.; Wang, X. Lignocellulose @activated clay nanocomposite with hierarchical nanostructure enhancing the removal of aqueous Zn (II). Polymers 2019, 11, 1710. [CrossRef] [PubMed]

56. Dang, J.; Wang, H.; Wang, C. Adsorption of toxic zinc by functionalized lignocellulose derived from waste biomass: Kinetics, isotherms and thermodynamics. Sustainability 2021, 13, 10673. [CrossRef]

57. Li, Q.; Tang, L.; Hu, J.; Jiang, M.; Shi, X.; Zhang, T.; Li, Y.; Pan, X. Removal of toxic metals from aqueous solution by biochar's derived from long-root Eichhornia crassipes. R. Soc. Open Sci. 2018, 5, 180966. [CrossRef]

58. Kayranli, B.; Gok, O.; Yilmaz, T.; Gok, G.; Celebi, H.; Seckin, I.Y.; Kalat, D. Zinc removal mechanisms with recycled lignocellulose: From fruit residual to biosorbent then soil conditioner. Water Air Soil Pollut. 2021, 232, 8. [CrossRef]

59. Ahmad, S.Z.N.; Wan, S.; Wan, N.; Ismail, A.F.; Yusof, N.; Mohd, Y.; Mohd, Z.; Aziz, F. Adsorptive removal of heavy metal ions using graphene-based nanomaterials: Toxicity, roles of functional groups and mechanisms. Chemosphere 2020, 248, 126008. [CrossRef] [PubMed]

60. AnĐukić, A.B.; Kumrić, K.; Vukelić, N.S.; Dimitrijević, M.; Baščarević, Z.D.; Kurko, S.; Matovic, L. Simultaneous removal of $\mathrm{Pb}^{2+}, \mathrm{Cu}^{2+}, \mathrm{Zn}^{2+}$ and $\mathrm{Cd}^{2+}$ from highly acidic solutions using mechanochemically synthesized montmorillonite- $\mathrm{kaolinite} / \mathrm{TiO}{ }_{2}$ composite. Appl. Clay Sci. 2015, 103, 20-27. [CrossRef] 